\title{
REGULATION OF PYRUVATE KINASE AND GLYCEROL-3-PHOSPHATE DEHYDROGENASE IN THE FREEZE TOLERANT GOLDENROD GALL FLY: ROLE IN POLYOL CRYOPROTECTANT PRODUCTION
}

\author{
by \\ Jean Abboud \\ B.Sc. (Hons.), 2012
}

A thesis submitted to the Faculty of Graduate and Postdoctoral Affairs in partial fulfillment of the requirements for the degree of

\section{Master of Science}

in

Biology

Carleton University

Ottawa, Ontario

(C)2015, Jean Abboud 
The undersigned hereby recommend to the Faculty of Graduate Studies and Research acceptance of this thesis

\title{
REGULATION OF PYRUVATE KINASE AND GLYCEROL-3-PHOSPHATE \\ DEHYDROGENASE IN THE FREEZE TOLERANT GOLDENROD GALL FLY: ROLE IN POLYOL CRYOPROTECTANT PRODUCTION
}

\author{
Submitted by \\ Jean Abboud, B.Sc. (Hons.) \\ Chair, Department of Biology \\ Thesis Supervisor \\ Carleton University
}

In partial fulfillment of the requirements for the degree of Master of Biology 


\begin{abstract}
Larvae of the goldenrod gall fly, Eurosta solidaginis, can survive winter temperatures as cold as $-55^{\circ} \mathrm{C}$ by using the freeze tolerance strategy of cold hardiness. This study examines pyruvate kinase (PK) and glycerol-3-phosphate dehydrogenase $(\mathrm{G} 3 \mathrm{PDH})$ that were purified from gall fly larvae acclimated to $5^{\circ} \mathrm{C}$ (control) and $-15^{\circ} \mathrm{C}$ (freeze-exposed). The roles that these enzymes play in polyol cryoprotectant synthesis and metabolic regulation were investigated. A primary focus was the potential for reversible post-translational modifications (PTMs) to regulate enzyme activity. Several PTMs were analyzed for PK and G3PDH from control and freeze-exposed gall fly larvae using dot-blot analysis. Results showed that low and high phosphate forms of each enzyme exist and these differ in kinetic properties, G3PDH also showed different levels of ubiquitination. Changes in substrate affinities and different interactions with endogenous sugars suggest that PK activity is maintained whereas G3PDH is inhibited during freezing.
\end{abstract}




\section{Acknowledgements}

I would like to start by thanking my parents who always believed in me and would sacrifice so much if it meant giving me a chance at a happy life.

A big part of my thanks has to go to my supervisor Dr. Ken Storey who had a profound impact on my life. Thank you for first letting me join your lab and then for looking past all my short-comings. You helped me learn a lot about science, the world, and myself. Thank you for all those movie Tuesdays and for the lab barbeques at your home. Also, thanks for letting me buy that fridge. Despite having the difficult job of running a big lab, you always kept my best interests at heart.

Thank you Jan Storey for all the incredible support and assistance. Of course I have to thank you for all the editing but you did a lot more than just that. Thank you for spending time showing us how to do dissections and the many more tricks around the lab. Thank you for constantly pointing me in the right direction and for always giving me more knowledge than I ask for because you know it can be beneficial.

I would like to thank all the Storey lab members who were supportive along the way. Neal Dawson and Ryan Bell, you were not only helpful during the more demanding graduate studies but were even especially critical during the beginning stages when I needed the most support. Having to balance several trainees at a time while pursuing a Ph.D. and all the responsibilities that come with it, you did an excellent job that made it possible for me to succeed in my career. I would also like to thank Zi-Jian Xiong and Christie Childers for all your help and support.

I would also like to thank Drs. Owen Rowland and Marc Ekker for making the time to offer me graduate level courses. 


\section{Table of Contents}

Acceptance Sheet $\quad$ ii

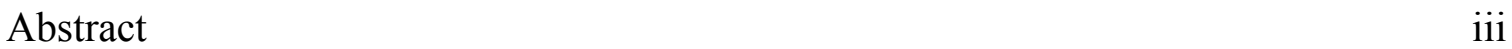

Acknowledgements $\quad$ iv

Table of Contents $\quad$ V

List of Abbreviations $\quad$ vi

List of Tables $\quad$ viii

List of Illustrations $\quad$ ix

Chapter 1: General introduction 1

Chapter 2: Pyruvate kinase in the goldenrod gall fly 14

Chapter 3: Glycerol-3-phosphate dehydrogenase in the goldenrod gall fly 42

$\begin{array}{ll}\text { Chapter 4: General discussion } & 63\end{array}$

$\begin{array}{ll}\text { References } & 72\end{array}$ 


\section{List of Abbreviations}

6PGDH - 6-phosphogluconate dehydrogenase

Acetyl-CoA - Acetyl coenzyme A

AMP, ADP, ATP - adenosine mono,-di,-or triphosphate

AMPK - AMP activated protein kinase

CHES - N-cyclohexyl-2-aminoethanesulfonic acid

DHAP - dihydroxyacetone phosphate

EDTA - ethylenediamine tetraacetatic acid

EGTA - ethyleneglycol bis tetraacetate acid

FBP - fructose-1,6-bisphosphate

G3P - glycerol-3-phosphate

G3PDH - glycerol-3-phosphate dehydrogenase

G6PDH - glucose-6-phosphate dehydrogenase

GAP - glyceraldehyde-3-phosphate

I50 - inhibitor concentration reducing enzyme velocity by $50 \%$

kD - kiloDalton

$\mathbf{K}_{\mathbf{m}}-$ substrate concentration producing half maximal enzyme activity

LDH - lactate dehydrogenase

MES - 2-(N-morpholino)ethanesulfonic acid

NAD, NADH - oxidized and reduced nicotinamide adenine dinucleotide

NADP, NADPH - oxidized and reduced nicotinamide adenine dinucleotide phosphate

PAGE - polyacrylamide gel electrophoresis 
PDH - polyol dehydrogenase

PEP - phosphoenolpyruvate

PFK - phosphofructokinase

PK - pyruvate kinase

PMSF - phenylmethysulfonyl fluoride

PPP - pentose phosphate pathway

PTM - post-translational modification

Q10 - increase in velocity per $10^{\circ} \mathrm{C}$ increase in temperature

SDS - sodium dodecyl sulfate

SCP - supercooling point

TBS, TBST - Tris-buffered saline with or without Tween-20

Tris - tris(hydroxymethyl)aminomethane

$\mathbf{V}_{\mathbf{m a x}}$ - maximal enzyme velocity 


\section{List of Tables}

Table Page

2.1 Purification of pyruvate kinase from freeze-tolerant gall fly larvae. 27

2.2 Kinetic parameters of purified PK from control and frozen gall fly. 28

2.3 Effect of sugars and an amino acid on the affinity constant for PEP of 29 PK from gall fly larvae.

3.1 Kinetic parameters of purified G3PDH from control and frozen gall 51 fly larvae.

3.2 Interaction of substrate affinity with the presence of cryoprotectants (glycerol, sorbitol) for purified G3PDH from control and frozen gall fly larvae.

3.3 The effect of sugars on the $\mathrm{I}_{50}$ urea of G3PDH from control and frozen gall fly larvae. 


\section{List of Illustrations}

Figure Page

1.1 Biosynthetic pathways for glycerol, sorbitol, and glucose 13 cryoprotectants.

2.1 SDS-PAGE gel showing the purification of PK from control gall flies.

2.2 The effect of $\mathrm{pH}$ on the $\mathrm{K}_{\mathrm{m}}$ PEP of PK from control and frozen gall flies.

2.3 Activity of PK from control and frozen gall fly larvae in the presence of the natural cryoprotectants accumulated by the insects: sorbitol (A) and glycerol (B).

2.4 The effect of adding sugars on the $\mathrm{I}_{50}$ value for urea of PK purified from control and frozen gall fly larvae.

2.5 Dot blot showing Pro-Q Diamond phosphoprotein staining of PK (and corresponding Coomassie blue staining of the dots) and quantification of the relative phosphorylation on PK purified from control versus frozen gall fly larvae.

2.6 Dot blots with antibodies assessing different posttranslational modifications and Coomassie protein staining of PK purified from control and frozen gall fly larvae.

3.1 SDS-PAGE gel showing purification of G3PDH from gall fly larvae.

3.2 Relative activity of purified G3PDH from control and frozen gall fly larvae in the presence of different concentrations of cryoprotectants glycerol or sorbitol.

3.3 Dot blots with different PTM antibodies and Coomassie protein staining of G3PDH from control and frozen gall fly larvae. 


\section{Chapter 1: \\ General Introduction}




\section{Freeze tolerance and diapause}

Of the countless animal adaptations found in every corner of the world, one in particular encompasses a bundle of physical challenges; survival of the harsh cold winters of higher latitudes. As days shorten and the sun's rays diminish vegetative growth comes to a halt, water becomes scarce, and freezing temperatures threaten the integrity of every cell. For organisms such as arthropods to survive these grueling months of blizzards and $-40^{\circ} \mathrm{C}$ temperatures, they not only need behavioural strategies but also cellular and metabolic adaptations. Behavioural strategies include reducing activity and seeking adequate shelter such as in trees, under forest floor leaf litter, or underground. Physiological strategies often include entry into diapause, a period of arrested growth characterized by strong metabolic rate depression. Protective physiological strategies are also used: either avoiding freezing by extensive supercooling (freeze avoidance) or accept the freezing of extracellular body fluids but prevent intracellular water from freezing (freeze tolerance). Cellular adaptations to deal with subcellular temperatures include proliferating defense mechanisms to either prevent (antifreeze proteins) or manage ice growth (ice nucleating agents) in the body, greatly elevate the concentrations of sugars and proteins to either promote either extreme supercooling (freeze avoidance) or keep intracellular water from freezing (freeze tolerance). Finally, metabolic adaptations are needed that include regulation of catabolic and anabolic pathways to achieve various goals; for example, inhibition of glycolysis can be used to push carbohydrates into the pathways that synthesize polyhydric alcohols as cryoprotectants.

Creatures that cannot rely on the protection and care from their parents during their development need to find strategies to survive to adulthood. Many species, 
including large numbers of insects, and many others, rely on the process of diapause to help them survive through regular and predictable environmental barriers to sufficient food and water (Tauber et al., 1986; Collier and Murphy, 1997). Diapause is a physiological process that delays development until there is a specific stimulus that triggers the return to normal growth (Dickson, 1949). This is especially important for many insect species with an annual life-cycle because growth and development is halted in the cold months of the year. For example, in a matter of a few weeks caterpillars may eat 27,000 times their body weight and grow to 1,000 times their initial size (Wagner, 2009; Triplehorn and Johnson, 2005). However, if they cannot find enough food, they may not be able to go through metamorphosis or be fertile as an adult. The onset of winter interrupts the larval growth stage but also offers a reliable cue to initiate diapause. An example is the carob moth, Ectomyelois ceratoniae, that interrupts the fifth instar of its larval stage when environmental temperatures decrease and overwinters in pomegranate fruit. It survives temperatures as low as $-9^{\circ} \mathrm{C}$ and months without eating by lowering its supercooling point (SCP; the temperature at which body water freezes spontaneously) and accumulating glycogen and lipids, glycogen providing the fuel to synthesize polyhydric alcohol cryoprotectants (Izadi and Heydari, 2014).

For large numbers of insects, winter survival relies on freeze tolerance and adaptations that protect their cells against rupture and severe dehydration (Danks, 1978). For this highly effective adaptation to work, the animal has to reduce the amount of intracellular "unbound" water content and control the start and spread of ice formation (Storey et al., 1981a; Storey and Storey, 1983b). The intracellular space remains unfrozen because of an increase in cryoprotectants, the control of bound and unbound water, an 
increase in solute concentrations and the initiation of extracellular ice formation via the action of nucleating agents (Morrissey and Baust, 1976; Storey et al., 1981a; Zachariassen, 1980). Forcing ice formation in extracellular compartments by using nucleating agents protects against uncontrolled crystallization in places where ice could cause physical damage and also sets up a system where water is drawn out of cells osmotically resulting in higher intracellular concentrations of solutes that further reduce the temperature at which intracellular freezing could occur. In the frozen state, individual cells are isolated from their environment and yet metabolism must continue to maintain viability despite the fact that fuel and oxygen supplies (normally delivered by hemolymph and trachea) to cells is cut off. Hence, survival in the frozen state can require altered regulation of the enzymes and pathways of energy metabolism without input from extracellular signals. In particular, enzymes involved in synthesis of polyols as cryoprotectants and in metabolic energy production require precise control. For example, the Antarctic midge, Belgica antarctica, a year-round freeze-tolerant insect, accumulates glucose, trehalose and erythritol to allow the larvae to survive freezing to as low as $-20^{\circ} \mathrm{C}$ and also endures whole body dehydration of up to $70 \%$ of total body water (Lee and Baust, 1981; Baust and Lee, 1983; Hayward et al., 2007).

Species that depend on freeze tolerance during the cold seasons experience reversible changes at the cellular level. Gall fly larvae are accumulating cryoprotectants during the fall season in response to certain seasonal triggers such as desiccation, which allows them to be ready for the event of freezing when the right temperature is reached (Gantz and Lee, 2014). However, the production of polyol cryoprotectants may cease at temperatures below $-8^{\circ} \mathrm{C}$ once the animal freezes (Storey et al., 1981b). The modification 
of metabolic fuel consumption also needs to change to prevent its depletion before the end of winter. This is often observed as a shift from lipid metabolism to exclusive carbohydrate consumption via glycolysis. Finally, glycolytic rate also has to be minimized to preserve sufficient glycogen as a winter fuel for metabolism and control lactate build-up. All these changes require timely enzymatic regulation, which may be accomplished by regulatory mechanisms such as reversible post-translational modification (PTM).

\section{Reversible post-translational modification}

A mechanism that can alter the activity of an enzyme or even shut it off completely for an extended amount of time is post-translational modification, which is the addition of a functional group to one or several amino acid residues of the primary structure. A common PTM that regulates the activity of many enzymes is reversible phosphorylation but there are numerous others, several of which (e.g. acetylation, methylation, ubiquitination, $\gamma$-carboxylation and nitrosylation) can affect properties of metabolic enzymes. PTMs alter the conformation of proteins or their charge state and lead to various functional changes in an enzyme such as altering enzyme activity, substrate affinity, sensitivity to activators or inhibitors, structural stability, protein-protein binding interactions or subcellular location (Cohen, 2002). Insects facing cold winters need to alter their metabolic patterns to ensure survival; necessary changes include synthesis of carbohydrate cryoprotectants, suppression of the SCP, control of water and cryoprotectant distribution, and implementing metabolic changes to enter diapause. These changes may be required to last a few days or a number of months. Since glycogen 
becomes a primary source of fuel and also a carbon source for cryoprotectant synthesis, altered regulation of the enzymes responsible for lipid and glycogen breakdown is needed. PTMs have been shown by our laboratory to regulate enzymes in such a way. For example, studies with the African clawed frog, Xenopus laevis, showed that liver lactate dehydrogenase (LDH) was altered during estivation by phosphorylation, demethylation and ubiquitination with a resulting increase in LDH activity (Katzenback et al., 2014).

Roles for reversible protein phosphorylation in the regulation of enzyme and protein function are very well known and have been extensively characterized for many years. The discovery of ubiquitination highlighted its major function; i.e. labeling proteins for degradation (Hershko, 1983; Ciechanover et al., 1984). However, new roles for ubiquitination have been emerging where the end result is not proteolysis. A notable more recent discovery is the role that ubiquitin plays in activating an enzyme involved in inflammatory and stress induced pathways (Wang et al., 2001). The signal transducer protein TRAF6 (from the TNF receptor associated factor protein family) combines with the dimeric ubiquitin-conjugating enzyme complex TRIKA1 to polyubiquitinate a lysine residue on the kinase TAK1. TAK1 is part of the protein kinase complex TRIKA2 and is activated by the lysine polyubiquitination. The activated TAK1 phosphorylates and activates IкB kinase and MAP kinase 6. Phosphorylated MAP kinase 6 stimulates the kinase activity of c-Jun amino-terminal kinase and p38 kinase. These kinases initiate signaling pathways that are involved in cell growth, differentiation, survival and apoptosis (Pearson et al., 2001). Stimuli that can be responsible for initiating these pathways include cytokines, ultraviolet irradiation, heat shock and osmotic shock (Ip and Davis, 1998). Our laboratory has recently reported post-translational ubiquitination of the 
metabolic enzyme LDH in dehydration-tolerant frogs, implicating its role in stressinduced enzymatic regulation (Katzenback et al., 2014; Abboud and Storey, 2013).

\section{The goldenrod gall fly larvae}

A highly valued model system for insect freeze tolerance studies is the goldenrod gall fly, Eurosta solidaginis. Reported for having survived winters as cold as $-55^{\circ} \mathrm{C}$, the third instar larvae of the gall fly live in stem galls on goldenrod plants; the tall woody stems of this plant means that the larvae often remain above the snow-pack throughout the winter where they are exposed to ambient air temperatures (Lee et al., 1995; Morrissey and Baust, 1976). With a SCP hovering around $-8^{\circ} \mathrm{C}$ in its freeze-tolerant state, the gall fly freezes when temperatures go below this value and over $60 \%$ of total body water can be converted to extracellular ice (Lee and Lewis, 1985). This is in fact one of its cold hardiness strategies, which is to initiate extracellular water crystallization after it is intracellularily immune to freezing and has reduced its water content sufficiently to protect against freezing internal injury. The gall fly larvae achieve intracellular cryoprotection by accumulating glycerol as temperatures cool in the autumn; the trigger temperature is around $15^{\circ} \mathrm{C}$ and maximum glycerol levels (about $360 \mu \mathrm{mol} / \mathrm{g}$ wet wt.) are reached when ambient temperatures are around $5^{\circ} \mathrm{C}$. Synthesis of a second cryoprotectant, sorbitol, is triggered at about $5^{\circ} \mathrm{C}$ and reaches its maximum at about $-10^{\circ} \mathrm{C}(\sim 120 \mu \mathrm{mol} / \mathrm{g}$ wet wt.; Storey et al., 1981b). Below this temperature the gall fly freezes, its metabolic rate is enormously depressed, glycolysis takes over as the main energy-producing pathway and the anaerobic product lactic acid accumulates (Storey et al., 1981b). A third critical adaptation for freeze tolerance is an increase of the portion of 
intracellular bound water (to soluble subcellular components) from $11 \%$ to $36 \%$ in larvae acclimated to $-30^{\circ} \mathrm{C}$ compared to $24^{\circ} \mathrm{C}$ (Storey and Storey, 1983b).

Depleting glycogen storage with decreasing temperature in the gall fly larvae has been shown to be accounted for by the production of glycerol, sorbitol, glucose and trehalose (Storey et al., 1981b). Production of polyol cryoprotectants such as these come to a stop at temperatures below $-10^{\circ} \mathrm{C}$ when the hemolymph is frozen. At temperatures above $-10^{\circ} \mathrm{C}$, aerobic metabolism is fully active and able to maintain energy stores (ATP, arginine phosphate). Below $-10^{\circ} \mathrm{C}$, oxidative metabolism is significantly reduced reflecting mitochondrial inactivity, which causes energy stores to decrease (Storey et al., 1981b). Limitation of oxygen supply in these conditions is the likely cause, which also accounts for the initiation of lactate production. However, lactate was only observed to increase slightly and remain at a constant level for the rest of the season (Storey and Storey, 1985; 1986).

The activity of a number of enzymes has been shown to change prior to and during freezing of the gall fly larvae. Enzymes that initiate and commit the break-down of glycogen such as glycogen phosphorylase and hexokinase showed an activation at the low temperatures where glycerol production began (Storey and Storey, 1981). Glycerol is produced by allowing carbon flux to flow through the pentose phosphate pathway (PPP) and/or down glycolysis with an inhibition at pyruvate kinase that promotes the diversion of the triose phosphates (glyceraldehyde-3-phosphate (GAP) and glycerol-3-phosphate (G3P) into glycerol production (Storey, 2004; Storey and Storey, 1983a; 1991; 2012). At lower temperatures where sorbitol begins to appear, the flow of carbon is blocked at the phosphofructokinase (PFK) locus to direct hexose phosphates into sorbitol production. 
Figure 1.1 outlines the biosynthetic pathways for glycerol, sorbitol, and glucose and their relation to enzymes from the PPP and glycolysis. An important aspect of the enzymatic regulation related to the production of both glycerol and sorbitol is the provision of NADPH for reducing power. The PPP is key to the NADPH production needed for polyol synthesis (Joanisse and Storey, 1994). During conversion of glycogen to glycerol and sorbitol, the activity of the first enzyme in the PPP, glucose-6-phosphate dehydrogenase (G6PDH), is increased (Storey et al., 1991). G6PDH is one of the two NADPH producing enzymes in the PPP, whereas the second enzyme, 6phosphogluconate dehydrogenase (6PGDH), is the rate-limiting step. 6PGDH is regulated in the gall fly to meet the demands for NADPH where it is activated at temperatures below $15^{\circ} \mathrm{C}$ but experiences conformational changes at $5^{\circ} \mathrm{C}$ that increase its activation energy, thereby inhibiting it. This reflects the ability of the gall fly to produce sorbitol at this temperature range and not at lower temperatures where it is near freezing (Holden and Storey, 1994).

Enzymes that are not related to cryoprotectant production were also found to be regulated to suppress unnecessary and metabolically expensive reactions during when insects are in the frozen state and/or when carbohydrate resources must be directed in to polyol synthesis. Pyruvate dehydrogenase is the link between glycolysis and the Krebs cycle; it converts pyruvate into acetyl coenzyme A (acetyl-CoA) and commits carbohydrates to either oxidation by mitochondria (via the Krebs cycle, electron transport cycle and oxidative phosphorylation) or to biosynthesis pathways that need 2-carbon building blocks (Lane, 2009). Recently, pyruvate dehydrogenase was found to be inhibited by $50 \%$ in the gall fly larvae during freezing by means of reversible 
phosphorylation, which supports the theory that mitochondrial aerobic metabolism is very strongly suppressed during frozen diapause (Rider et al., 2011). Another critical enzyme that is regulated in the survival mechanisms of the gall fly is the AMP-activated protein kinase (AMPK). AMPK acts by switching target enzymes off through phosphorylation and is particularly geared to shutting of biosynthesis when cellular energy levels are low (i.e. AMP levels are high). Two well-known targets of AMPK are acetyl-CoA carboxylase that catalyzes the first step in lipogenesis, and HMG-Co reductase that controls carbon entry into steroid biosynthesis. Activity of AMPK was enhanced in frozen gall fly larvae, which may serve the purpose of stimulating glucose uptake, inhibiting glycogen synthesis, inhibiting protein synthesis, and shutting off anabolic pathways. The general effect of AMPK activation is to reduce ATP consumption in favor of maintaining ATP pools (Rider et al., 2011).

\section{Pyruvate kinase and glycerol-3phosphate dehydrogenase}

Pyruvate kinase (PK; EC: 2.7.1.40) catalyzes the final step in glycolysis before carbon flow is split between aerobic and anaerobic metabolism. Its reaction is:

$$
\text { Phosphoenolpyruvate }(\mathrm{PEP})+\mathrm{ADP} \rightarrow \text { Pyruvate }+ \text { ATP }
$$

PK is one of the two ATP-producing steps of glycolysis and is therefore an important enzyme of anaerobic metabolism. Since it has already been shown that the aerobic pathway of pyruvate oxidation in frozen gall fly larvae is shut down, the alternative utilization as an anaerobic fermentative substrate must be considered. This is the conversion of pyruvate to lactate by LDH in a process that results in a build-up of this product and restores the NAD that is needed to keep glycolysis running. As previously 
mentioned, lactate concentrations have been observed to rise as the temperature of the gall fly larvae decrease past its freezing point but they stay level for the remainder of the winter (Storey and Storey, 1985; 1986). Therefore, the activity of PK may be closely regulated to reflect the critical dependence of the gall fly on anaerobic energy production. Chapter 2 of this thesis presents a study of the kinetics and regulation of PK in the gall fly larvae in response to freezing.

Glycerol-3-phosphate dehydrogenase (G3PDH; also referred to as $\alpha \mathrm{GPDH}$; EC: 1.1.1.8) links glycolysis to lipid metabolism by catalyzing the reversible reaction: Dihydroxyacetone phosphate (DHAP) $+\mathrm{NADH}+\mathrm{H}^{+} \leftrightarrow \mathrm{G} 3 \mathrm{P}+\mathrm{NAD}^{+}$. DHAP is an intermediary of glycolysis that is normally interconverted with GAP to continue down the glycolytic chain to the production of pyruvate. Conversion of DHAP by G3PDH to G3P can lead to the production of glycerol as a cryoprotectant (after dephosphorylation) or G3P can be use in various biosynthesis reactions, particularly in triglyceride and phospholipid synthesis (Storey, 2004). As a reversible reaction, G3PDH can also be used to direct G3P into glycolysis from the catabolism of lipids (Larsson et al., 1998). A second noteworthy function of G3PDH is its participation in the G3P shuttle that acts to transfer NADH reducing equivalents from the cytosol into the electron transport chain of the mitochondria where it is reoxidized to DHAP by G3P oxidase (Shen et al., 2003; Sacktor, 1976). Insects rely on this shuttle more greatly than they do on the malate-aspartate shuttle which performs the same function in vertebrate species. G3PDH has been shown to play a role in hibernation and anoxic stress (de la Roche et al., 2012; Alarcon et al., 2012). Diapausing gall fly larvae have to protect their fat reserves for use in fueling the spring metamorphosis into the pupal and adult states and supplying 
the energy needs of the non-feeding adult stage; indeed, analysis of gall fly larvae showed constant lipid content throughout winter (Storey and Storey, 1992; Joanisse and Storey, 1996). Therefore, the implications of G3PDH on the survival of the gall fly larvae pertaining to lipid versus carbohydrate metabolism and NADH shuttling are of great interest. Chapter 3 of this thesis presents a study of the kinetics and regulation of G3PDH in the gall fly larvae in response to freezing.

\section{Hypotheses}

I hypothesized that regulation of $\mathrm{PK}$ and G3PDH by post-translational modifications is an important part of freeze tolerance and diapause in overwintering gall fly larvae. Three specific hypotheses were challenged in this study:

1. The activity of PK is regulated in the goldenrod gall fly, Eurosta solidaginis, to protect its cells against severe energy depletion in the absence of oxidative phosphorylation.

2. The activity of G3PDH is suppressed in the goldenrod gall fly, Eurosta solidaginis, because of the absence of lipogenesis and mitochondrial activity in the frozen state, and the greater importance of maintaining glycolysis.

3. Reversible PTMs play a role in the regulation of PK and G3PDH in the goldenrod gall fly, Eurosta solidaginis, for winter survival. 


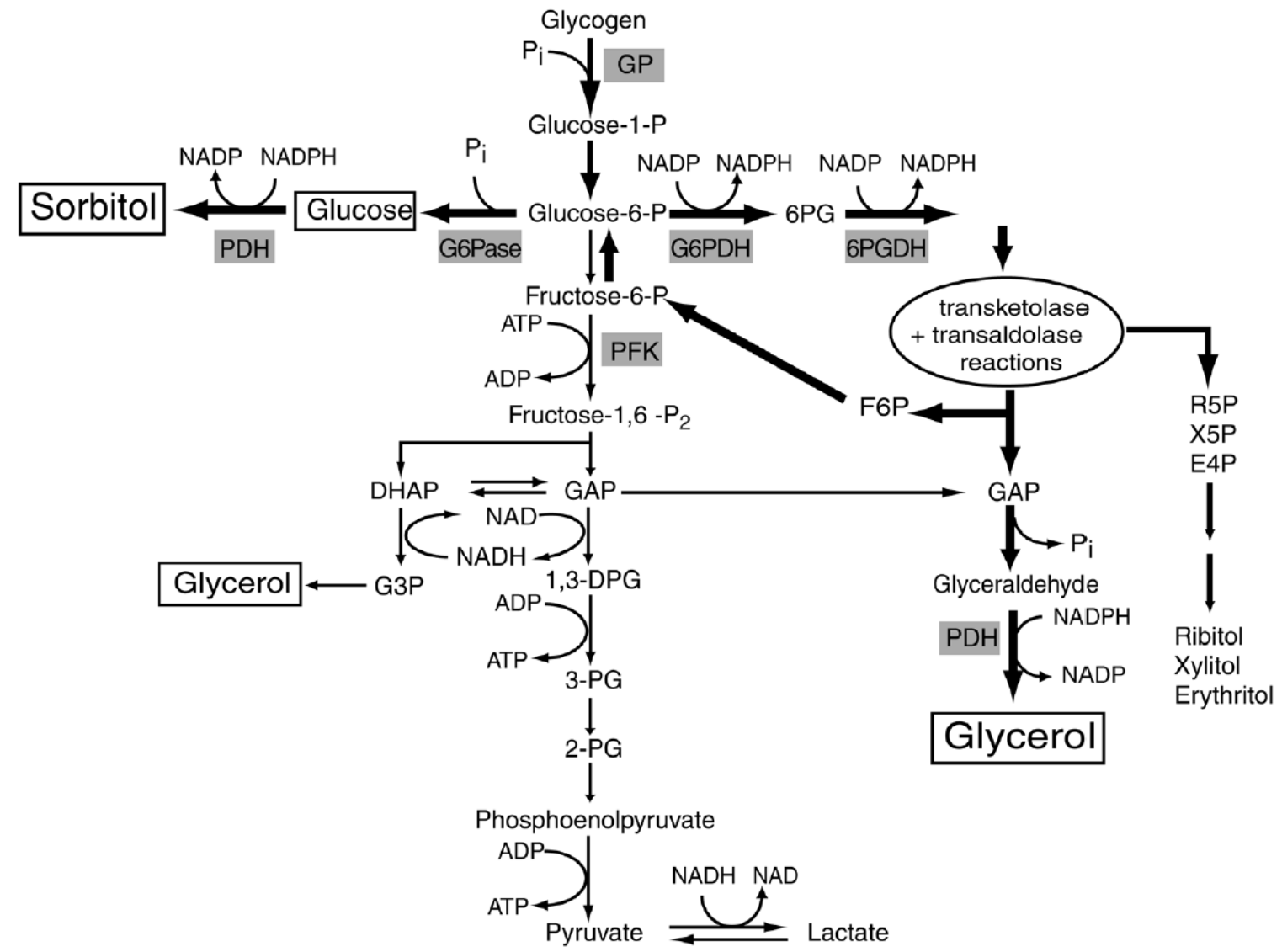

Figure 1.1. Biosynthetic pathways for glycerol, sorbitol, and glucose cryoprotectants. Glycogen is the carbon source and enzymes of glycolysis and the pentose phosphate cycle (PPP) are used. Glycerol in insects is primarily made from the glyceraldehyde-3phosphate (GAP) output of the PPP using NADPH reducing power that is also generated by the PPP. Outputs of four and five carbon sugar phosphates from the PPP can also be converted to their corresponding polyols after phosphate removal and then conversion of sugar to polyol by the enzyme polyol dehydrogenase (PDH). Other enzymes in shaded boxes are: GP, glycogen phosphorylase; G6Pase, glucose-6-phosphatase; G6PDH, glucose-6-phosphate dehydrogenase; 6PGDH, 6-phosphgluconate dehydrogenase; PFK, 6-phosphofructo-6-kinase (modified from Storey, 2004). 


\section{Chapter 2: \\ Pyruvate kinase in the goldenrod gall fly}




\section{Introduction}

Winter survival of gall fly larvae in the frozen state depends on ATP production by fermentative glycolysis and a net depletion of carbohydrate fuel reserves to supply both energy needs and the production of huge amounts of polyol cryoprotectants (Storey and Storey, 1985). However, larval investment in cryoprotectant synthesis from glycogen is relatively inexpensive in metabolic terms because of the outcomes for glycerol and sorbitol at the end of the cold season. It has been shown that sorbitol is converted back to glycogen when environmental temperatures rise again in the spring whereas glycerol levels remain constant until the end of the third instar and then are probably catabolized as a fuel source for metamorphosis (Storey and Storey, 1983a; 1991). Freezing is thought to trigger a shift towards glycolysis because a rise in glucose-6-phosphate and lactate are observed in response to just a few hours at $-16^{\circ} \mathrm{C}$ temperature (Storey and Storey, 1985). However, the energy reserves of the larvae do decline steadily as early as 1-2 weeks (by $70 \%$ for arginine phosphate and 50\% for ATP) and continue to diminish through 6 to 12 weeks of continuous freezing (by $95 \%$ for arginine phosphate and $75 \%$ for ATP; Storey and Storey, 1985). Despite this depletion of energy during a long state of inactivity, 94\% of larvae were observed to survive up to 12 weeks at this temperature (Storey and Storey, 1985).

The activity of PK was shown to remain constant in gall fly larvae throughout winter but dropped in the spring before the pupal stage (Joanisse and Storey, 1994), probably related to a reduced need to depend on glycolytic metabolism once there was no longer much chance of freezing. However, in the autumn/winter (prior to entry into the frozen state), PK was observed to be cold-inhibited in response to temperature decreases 
from $23-13^{\circ} \mathrm{C}$ as assessed by the accumulation of PEP and a decrease in pyruvate (Storey and Storey, 1983a). This likely served the purpose of restricting carbon flow through glycolysis to allow cryoprotectant synthesis. However, further temperature decline did not alter PEP and pyruvate levels, indicating a potential for regulation further up the glycolytic pathway (PFK locus) or an unknown PK regulation. LDH activity was likewise maintained during the winter and increases by March (Joanisse and Storey, 1994). As a result, the importance of pyruvate production becomes relevant in order to supply LDH with the substrate needed to regenerate NAD for glycolysis. This led to the question of whether PK was modified or regulated in such a way to allow it to maintain its activity during the winter in spite of the low temperature and fluctuating carbohydrate intermediates. PK has been the subject of many studies because of its crucial role both in sustaining glycolytic ATP production and in acting as the final regulatory step in the glycolytic pathway. Indeed, once circulation is halted by freezing, the gall fly must rely on anaerobic metabolism to preserve its basal metabolic needs for what could be many weeks until thawing occurs (Storey and Storey, 1985).

The present study notably focused on the role of reversible PTMs as a regulatory mechanism of PK activity and kinetics in response to freezing. PK and PFK from the spadefoot toad, Scaphiopus couchii, have been shown by our laboratory to be reversibly phosphorylated to regulate their roles in the transition between dormant and active state during estivation (Cowan and Storey, 1999). Reversible phosphorylation has major regulatory effects on a variety of enzymes of intermediary metabolism and there is evidence of this PTM regulating several enzymes in gall fly larvae such as pyruvate dehydrogenase as mentioned in the previous chapter. A role for PTMs in enzymatic 
regulation in cold-hardy animals is only beginning to be investigated such as a recent demonstration from our laboratory that LDH from skeletal muscle of the freeze tolerant wood frog, Rana sylvatica, is deacetylated and possibly ubiquitinated in response to freezing (Abboud and Storey, 2013). The present study analyzes purified PK from goldenrod gall fly larvae, evaluating the effects of whole animal freezing exposures on PK properties and assessing the potential involvement of different PTMs as a regulatory mechanism.

\section{Methods}

\section{Chemicals and Animals}

Chemicals were purchased from Sigma Chemical Company (St. Louis, MO) or Bioshop (Burlington, ON). Goldenrod galls containing freeze tolerant Eurosta solidaginis larvae were collected in October from fields in the Ottawa region. First, insects were acclimated for three weeks in an incubator set at $5^{\circ} \mathrm{C}$. A portion of insects were then sampled by being rapidly removed from the galls and flash-frozen in liquid nitrogen. The remainder were kept at $-5^{\circ} \mathrm{C}$ for two and a half weeks and then moved to a $-15^{\circ} \mathrm{C}$ freezer for another two and a half weeks. Then, they were rapidly flash-frozen in liquid nitrogen as the $5^{\circ} \mathrm{C}$ insects. Insects were stored at $-80^{\circ} \mathrm{C}$ until use.

\section{Preparation of tissue extracts and enzyme purification}

Insects were quickly weighed and mixed 1:5 w:v in ice-cold buffer A (10 mM potassium phosphate buffer, $\mathrm{pH} 7.0,10 \% \mathrm{v} / \mathrm{v}$ glycerol, $5 \mathrm{mM}$ 2-mercaptoethanol, $1.5 \mathrm{mM}$ EDTA, $1.5 \mathrm{mM}$ EGTA, $25 \mathrm{mM} \beta$-glycerophosphate) that contained protein kinase 
(EDTA, EGTA) and protein phosphatase ( $\beta$-glycerophosphate) inhibitors. After the quick addition of a few crystals of phenylmethylsulfonyl fluoride (PMSF), the sample was immediately homogenized on ice with a Diamed Pro 200 homogenizer. Homogenates were centrifuged at 10,000 rpm for $30 \mathrm{~min}$ at $4^{\circ} \mathrm{C}$ in an Eppendorf Centrifuge $5810 \mathrm{R}$ and the supernatant was stored on ice. A $3 \mathrm{~mL}$ aliquot of supernatant was then diluted 1:2 v:v in buffer A and loaded onto a $5 \times 1 \mathrm{~cm}$ column of hydroxyapatite (bead bed at $1 \mathrm{~cm}$ from bottom) equilibrated in buffer A and washed to remove unbound protein. The wash fractions (PK does not bind this column) containing abundant PK activity were pooled and loaded onto a phosphocellulose column equilibrated in buffer B (same as buffer A but with $10 \mathrm{mM}$ MES buffer, $\mathrm{pH}$ 6.0), washed and eluted with $40 \mathrm{~mL}$ of buffer $\mathrm{A}$ containing $10 \mathrm{mM}$ Mg-ATP. The fractions with highest activity were pooled and applied to a Cibacron blue column equilibrated in buffer $\mathrm{C}$ (same as buffer $\mathrm{A}$ but $10 \mathrm{mM}$ Tris buffer, $\mathrm{pH}$ 8.0), washed and eluted with a gradient of 0-2 $\mathrm{M} \mathrm{KCl}$ in buffer C. Purified PK was collected for enzyme assay and a portion kept for dot blot analysis.

\section{SDS-Polyacrylamide gel electrophoresis}

The purity of PK was verified by running samples on SDS-PAGE, followed by staining with silver according to the following procedure. Samples of purified PK were concentrated 5-fold in $2 \mathrm{~mL}$ Centricons (Millipore Bioscience) by centrifugation at 4000 rpm for $30 \mathrm{~min}$ in an Eppendorf Centrifuge 5810 R. Concentrated purified enzyme was mixed 2:1 v:v with SDS loading buffer (100 mM Tris buffer, $\mathrm{pH}$ 6.8, 4\% w:v SDS, 20\% v:v glycerol, $0.2 \% \mathrm{w}: \mathrm{v}$ bromophenol blue) with $10 \% \mathrm{v}: \mathrm{v} 2$-mercaptoethanol added immediately before use and boiled for $5 \mathrm{~min}$, cooled on ice and frozen at $-20^{\circ} \mathrm{C}$. Aliquots 
(30 $\mu \mathrm{L}$ ) of thawed, well-mixed sample were added into the wells of 10\% SDS-PAGE gels. Gels were run at $180 \mathrm{~V}$ for $30 \mathrm{~min}$ in running buffer containing $25 \mathrm{mM}$ Tris-base, $250 \mathrm{mM}$ glycine and $0.1 \% \mathrm{w}: \mathrm{v}$ SDS. Genedirex $10.5-175 \mathrm{kD}$ protein ladders were run in selected lanes to assess the subunit molecular mass of PK.

\section{Enzyme assays}

PK activity was measured by coupling its reaction product (pyruvate) with the consumption of NADH by LDH. The reaction was monitored at $340 \mathrm{~nm}$ using a Multiskan Spectrum microplate reader. Optimal assay conditions for the forward reaction were determined to be $50 \mathrm{mM}$ Tris $\mathrm{pH}$ 7.2, $50 \mathrm{mM} \mathrm{KCl,} 5 \mathrm{mM} \mathrm{MgCl} 2,2 \mathrm{mM}$ ADP, 1 mM PEP, $0.15 \mathrm{mM} \mathrm{NADH}$, and 0.5 units purified LDH from Lactobacillus leichmanii (Sigma) in a $200 \mu \mathrm{L}$ total volume; assays were typically started by the addition of $1 \mu \mathrm{L}$ of purified PK enzyme. Routine assays were run at room temperature $\left(22^{\circ} \mathrm{C}\right) . \mathrm{I}_{50}$ values for PEP and ADP were determined at constant, suboptimal co-substrate concentrations. I50 values for all other compounds were determined at constant, subsaturating levels of substrate. For analysis of the $\mathrm{pH}$ dependence of PK substrate affinity, assays were conducted at $22^{\circ} \mathrm{C}$ under optimal substrate concentrations in different $50 \mathrm{mM}$ buffers: MES (pH 6.5), Tris (pH 7-9), or CHES (pH 9.5-10).

Soluble protein concentrations were determined using the Coomassie blue G-250 dye-binding method with the Bio-Rad Laboratories prepared reagent and bovine serum albumin as the standard. 


\section{Dot blots}

Dot blots were used to analyze and identify protein post-translational modifications using the method of Abboud and Storey (2013). Purified PK was applied to nitrocellulose membranes using a Bio-Dot ${ }^{\circledR}$ microfiltration apparatus that was prewashed twice with Tris-buffered saline (TBS: $20 \mathrm{mM}$ Tris base, $140 \mathrm{mM} \mathrm{NaCl}$, pH 7.6). In brief, samples passed through the apparatus by gravity and were then washed twice with TBST (TBS containing $0.05 \% \mathrm{v} / \mathrm{v}$ Tween-20). The membrane was sectioned with a razor blade into multiple pieces for probing with different antibodies, followed by three 5 min washes with TBST, blocking with $1 \mathrm{mg} / \mathrm{ml}$ poly(vinyl alcohol) in TBST for $30 \mathrm{~s}$, and then washing again with TBST as above. Membranes were then incubated with one of six primary antibodies overnight at $4^{\circ} \mathrm{C}$ : anti-phosphotyrosine (Invitrogen; cat. \#136600), anti-phosphothreonine (Invitrogen; cat. \#718200), anti-phosphoserine (Invitrogen; cat. \#618100), anti-methyl lysine (Biosciences Inc.; cat. \# SPC-158F), anti-acetyl (Santa Cruz Biotechnology; cat. \# sc 8663-R,), or anti-ubiquitin (Abcam; cat. \# ab19247), each diluted 1:1000 v:v in TBST. Unbound primary antibody was removed with three $5 \mathrm{~min}$ washes with TBST and then the membranes were incubated with HRP-conjugated antirabbit or anti-mouse secondary antibody (BioShop, diluted 1:4000 v:v in TBST) for 30 min at room temperature, followed by three 5 min washes with TBST. Membranes were then developed using Western Lighting Chemiluminescence Plus reagents (NEN, Perkin Elmer) following manufacturer's protocols, washed three times for $5 \mathrm{~min}$, and signal was detected using enzymatic chemiluminescence. Detection used the ChemiGenius Bioimaging System (Syngene, MD) and dot densities were quantified using GeneTools software (v3.00.02). Subsequently, membranes were re-stained for 5 min with Coomassie 
blue (25\% w/v Coomassie Brilliant Blue $\mathrm{R}$ in 50\% v/v methanol, $7.5 \% \mathrm{v} / \mathrm{v}$ acetic acid) and destained for $10 \mathrm{~min}$ with destaining mix [50\% v/v methanol, 10\% v/v acetic acid in distilled-deionized water $\left.\left(\mathrm{ddH}_{2} \mathrm{O}\right)\right]$. Phosphoprotein dot intensities were normalized against their corresponding Coomassie blue stained dot to correct for any variations in sample loading.

\section{ProQ diamond phosphoprotein blot staining}

In some instances, the dot blot procedure was followed by staining with Pro-Q ${ }^{\circledR}$ Diamond phosphoprotein stain (Invitrogen, Eugene, OR). In this case, the following modifications of the procedure were used. After loading protein onto the membrane, it was placed face down in fixing solution (7\% acetic acid, $10 \%$ methanol, $\left.83 \% \mathrm{ddH}_{2} \mathrm{O}\right)$

and incubated for $10 \mathrm{~min}$ followed by washing four times in $\mathrm{ddH}_{2} \mathrm{O}$ for $5 \mathrm{~min}$ each. The membrane was then immersed in $25 \mathrm{~mL}$ of Pro-Q ${ }^{\circledR}$ Diamond phosphoprotein blot stain (1000x diluted in ProQ phosphoprotein dot buffer) for $15 \mathrm{~min}$. The membrane was destained with three 5 min washes in ProQ dot blot destaining solution ( $15 \mathrm{~mL}$ acetic

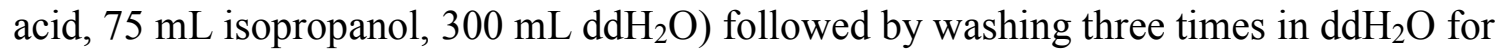
5 min each. Fluorescent bands on the membrane were visualized with the ChemiGenius and dot intensities were quantified. Subsequently, membranes were restained with Coomassie blue as described above.

\section{Data and Statistical Analysis}

A Microplate Analysis (MPA) Program was used to analyze enzyme rates and kinetic parameters were derived using a nonlinear least squares regression computer 
program, Kinetics 3.51 (Brooks 1992). Microsoft Excel 2010 and QI Macros software was used for all univariate and error plot analysis. As appropriate, statistical analysis used either the Student's independent t-test or a one-way ANOVA linked with Tukey's posthoc test (Ennos 2006). Values for 'n' denote the number of independent preparations of enzyme tested, each preparation being derived from a pool of at least 10 E. solidaginis larvae.

\section{Results}

Purification of Pyruvate Kinase

PK was purified from control $\left(5^{\circ} \mathrm{C}\right.$ acclimated $)$ and frozen $\left(-15^{\circ} \mathrm{C}\right.$ acclimated $)$ gall fly larvae using a three-step method. Table 2.1 shows the purification steps and Figure 2.1 shows a representative SDS-PAGE gel for PK purified from control larvae. The first purification step was a hydroxyapatite column that was used as a negative purification step since PK passed directly through the column but leaving nearly half of the total protein behind. The second step was elution off a phosphocellulose affinity column using a $10 \mathrm{mM}$ Mg-ATP bump. The third step was a Cibacron blue column using elution with a $\mathrm{KCl}$ gradient. The negative hydroxyapatite column gave a 1.57 -fold purification and a yield of $81.6 \%$ for control PK and a 1.49-fold purification and a yield of $89.0 \%$ for frozen PK. The phosphocellulose column raised the fold purification to 4.81-fold with a net $47.3 \%$ yield for control and a 5.93 -fold purification and a yield of $52.8 \%$ for frozen. The Cibacron blue column raised the overall final fold purification to 15.28-fold for control PK with a 101.8\% yield and a 16.66 -fold purification and a yield of 79.3\% for PK from frozen larvae. SDS-PAGE analysis showed single bands of PK 
protein for all purified preparations; Figure 2.1 shows an example for purified PK from control gall fly larvae. The calculated subunit molecular mass of gall fly PK was $61.9 \pm$ $1.0 \mathrm{kD}$ ( $\mathrm{n}=2$ separate purifications), very close to the value for commercially prepared PK from Lactobacillus leichmanii seen in lane $1(65.4 \mathrm{kD})$. Another example is the genetically closer mouse, Mus musculus, that has an almost identical subunit molecular weight of $62 \mathrm{kD}$ and a native tetrameric structure (Kim et al., 2008).

Activities and kinetic analysis of purified PK from control and frozen gall fly larvae

Table 2.2 shows kinetic parameters for PK purified from control and frozen gall fly larvae. There was no significant difference in the $V_{\max }$ of purified PK (8.05-7.55 U/g) between the two insect states when assayed under optimal assay conditions at $\mathrm{pH} 7.2$ and $22^{\circ} \mathrm{C}$. However, the Michaelis constant $\left(\mathrm{K}_{\mathrm{m}}\right)$ for PEP did differ significantly between control $(0.126 \pm 0.005 \mathrm{mM})$ and frozen $(0.150 \pm 0.003 \mathrm{mM})$ states $(\mathrm{p}<0.01, \mathrm{n}=4)$ but the $\mathrm{K}_{\mathrm{m}}$ value for ADP did not differ. Inhibition of PK by its substrates PEP and ADP was similar between the enzyme from control and frozen insects with a stronger inhibition observed for PEP. Values for $\mathrm{I}_{50}$ (concentration that reduces activity by $50 \%$ ) were $\sim 3.0 \mathrm{mM}$ for PEP and 10.0-10.4 mM for ADP (Table 2.2).

The effects of $\mathrm{pH}(6.5-10)$ on the $\mathrm{K}_{\mathrm{m}}$ PEP were also evaluated for purified PK from control and frozen larvae (Figure 2.2). The $\mathrm{K}_{\mathrm{m}}$ was similar between control and frozen at extreme ends of the $\mathrm{pH}$ range tested (6.5 and 10.0). However, the $\mathrm{K}_{\mathrm{m}}$ PEP for frozen PK showed a left-ward shift at $\mathrm{pH}$ values between the extremes and were significantly different than corresponding control values except at $\mathrm{pH} 8.5(\mathrm{p}<0.05, \mathrm{n}=3)$. The effect of $\mathrm{pH}$ on $\mathrm{K}_{\mathrm{m}}$ PEP followed a two peak pattern peaking at 7.2 and 9-9.5. The 
effect of sorbitol and glycerol, the polyhydric alcohols that accumulate as cryoprotectants in gall fly larvae, were tested on the activity of $\mathrm{PK}$ at $22^{\circ} \mathrm{C}$. Figure 2.3 shows that neither glycerol nor sorbitol had an effect on PK activity from control or frozen larvae at concentrations above, at, and below physiological levels in frozen gall fly ( $\sim 330 \mathrm{mM}$ for glycerol and $\sim 105 \mathrm{mM}$ for sorbitol).

The effect of other sugars and related molecules were examined on PK from gall fly larvae. The $\mathrm{K}_{\mathrm{m}}$ of PEP was measured at $\mathrm{pH} 7.2$ in the presence of L-alanine, glucose, or two levels of G3P (Table 2.3). In the presence of $5 \mathrm{mM}$ alanine, $\mathrm{K}_{\mathrm{m}}$ PEP decreased significantly and remained in the same ratio between control and frozen PK (frozen being greater). In the presence of $30 \mathrm{mM}$ glucose, $\mathrm{K}_{\mathrm{m}}$ PEP of control went up and that of frozen went down just enough to no longer be significantly different. In the presence of $2.5 \mathrm{mM}$ G3P, $K_{m}$ PEP for control and frozen was $50 \%$ of its value without G3P. Finally, in the presence of $52.5 \mathrm{mM} \mathrm{G3P,} \mathrm{K}_{\mathrm{m}}$ PEP remained unchanged for both control and frozen PK (Table 2.3).

\section{Structure Stability}

Several compounds were found to inhibit PK: glucose, AMP, ATP, sulfate, oxalate, alanine, G3P, cysteine, and $\mathrm{H}_{2} \mathrm{O}_{2}$ (Table 2.2). No compound mentioned in the literature was found to activate PK. Table 2.2 shows the $\mathrm{I}_{50}$ values for the listed compounds that were measureable and found relevant to the study. The $\mathrm{I}_{50}$ values for AMP was approximately $44 \%$ greater for frozen $(49.2 \pm 1.4 \mathrm{mM})$ than control $(34.7 \pm 0.5$ $\mathrm{mM} ; \mathrm{p}<0.005, \mathrm{n}=3)$. G3P also had significantly different $\mathrm{I}_{50}$ values for control $(61.5 \pm 2.1$ 
$\mathrm{mM})$ and frozen $(73.1 \pm 1.3 \mathrm{mM} ; \mathrm{p}<0.05, \mathrm{n}=3)$. Oxalate had the highest inhibitory effect on PK (lowest $\mathrm{I}_{50}$ ) but $\mathrm{I}_{50}$ values were not different between the two insect states.

The effect of high concentrations of urea on PK was assessed by analyzing the $\mathrm{I}_{50}$ value for urea in the absence versus presence of various sugar additives (Figure 2.4). In the absence of any additive, the $\mathrm{I}_{50}$ value for urea was significantly higher $(\sim 75 \%)$ for PK from frozen larvae compared to the control enzyme $(\mathrm{p}<0.01, \mathrm{n}=4)$. Both glucose increased the $\mathrm{I}_{50}$ urea for control and frozen PK but glycerol only increased the $\mathrm{I}_{50}$ urea of control PK. Sorbitol did not change the $\mathrm{I}_{50}$ urea of control PK but significantly decreased it for frozen PK $(\mathrm{p}<0,01, \mathrm{n}=4)$. Glucose and glycerol added together raised the $\mathrm{I}_{50}$ urea of control PK to the same level as with glucose or glycerol alone whereas that of frozen PK was significantly decreased $(\mathrm{p}<0,01, \mathrm{n}=4)$. When all three sugars were added together, there was no additional effect.

\section{Dot blotting for post-translational modifications}

Pro-Q Diamond phosphoprotein stain was used to assess the relative phosphorylation state of purified PK from control and frozen gall fly larvae. Pro-Q dot intensities were standardized against the corresponding intensity of the same PK dot after restaining with Coomassie blue. Standardized Pro-Q fluorescence dot intensities were significantly different between control and frozen conditions indicating a change in the relative protein phosphorylation between the two states (Figure 2.5). Other potential posttranslational modifications of gall fly PK were then assessed by dot blotting using purified preparations of control and frozen PK and antibodies that detected different PTMs on proteins. Frozen PK showed a significantly higher level of phosphorylation on 
threonine residues $(\sim 65 \%)$ than control PK $(\mathrm{p}<0.005, \mathrm{n}=8$; Figure 2.6$)$. However, a comparison of control versus frozen PK showed no significant differences between the two enzyme forms with respect to any other PTM: phosphoserine, phosphotyrosine, methyl-lysine, acetylation or ubiquitination (Figure 2.6). 
Table 2.1. Purification of pyruvate kinase from freeze-tolerant gall fly larvae.

\begin{tabular}{|c|c|c|c|c|c|c|}
\hline Tissue & Step & $\begin{array}{l}\text { Total } \\
\text { protein } \\
\text { (mg) }\end{array}$ & $\begin{array}{l}\text { Total } \\
\text { activity } \\
\text { (Units) }\end{array}$ & $\begin{array}{l}\text { Yield } \\
(\%)\end{array}$ & $\begin{array}{l}\text { Fold } \\
\text { purification }\end{array}$ & $\begin{array}{l}\text { Specific } \\
\text { Activity } \\
\text { (U/g) }\end{array}$ \\
\hline \multirow[t]{4}{*}{ Control } & Crude & 18705 & 9.85 & $\mathrm{~N} / \mathrm{A}$ & $\mathrm{N} / \mathrm{A}$ & 0.53 \\
\hline & Hydroxyapatite & 9711 & 8.04 & $81.6 \%$ & 1.57 & 0.83 \\
\hline & Phosphocellulose & 1839 & 4.66 & $47.3 \%$ & 4.81 & 2.53 \\
\hline & Cibacron blue & 1246 & 10.03 & $101.8 \%$ & 15.28 & 8.05 \\
\hline \multirow[t]{4}{*}{ Frozen } & Crude & 24744 & 11.21 & $\mathrm{~N} / \mathrm{A}$ & $\mathrm{N} / \mathrm{A}$ & 0.45 \\
\hline & Hydroxyapatite & 14743 & 9.98 & $89.0 \%$ & 1.49 & 0.68 \\
\hline & Phosphocellulose & 2202 & 5.92 & $52.8 \%$ & 5.93 & 2.69 \\
\hline & Cibacron blue & 1177 & 8.89 & $79.3 \%$ & 16.66 & 7.55 \\
\hline
\end{tabular}


Table 2.2. Kinetic parameters of purified PK from control and frozen gall fly. All assays were carried out at room temperature $\left(22^{\circ} \mathrm{C}\right)$ and $\mathrm{pH} 7.2 . \mathrm{K}_{\mathrm{m}}$ values were determined at optimal co-substrate concentration, either $1 \mathrm{mM}$ PEP or $2 \mathrm{mM}$ ADP. $\mathrm{I}_{50}$ values were determined at sub-optimal concentrations of both substrates, $0.5 \mathrm{mM}$ PEP or $1 \mathrm{mM}$ ADP. Data are means $\pm \mathrm{SEM}, \mathrm{n}=3{ }^{\mathrm{a}}{ }^{\mathrm{a}}$ - Significantly different from the corresponding control value using Student's test. NS - not significant.

\begin{tabular}{llll}
\hline Kinetic parameter $(\mathrm{mM})$ & Control & Frozen & P-value \\
\hline $\mathrm{K}_{\mathrm{m}}$ PEP, $\mathrm{pH} 7.2$ & $0.126 \pm 0.005$ & $0.150 \pm 0.003^{\mathrm{a}}$ & $<0.01, \mathrm{n}=4$ \\
$\mathrm{~K}_{\mathrm{m}}$ ADP, $\mathrm{pH} 7.2$ & $0.309 \pm 0.004$ & $0.297 \pm 0.003$ & $\mathrm{NS}, \mathrm{n}=3$ \\
$\mathrm{I}_{50}$ PEP & $3.01 \pm 0.07$ & $3.05 \pm 0.02$ & $\mathrm{NS}, \mathrm{n}=2$ \\
$\mathrm{I}_{50}$ ADP & $10.0 \pm 0.10$ & $10.4 \pm 0.28$ & $\mathrm{NS}, \mathrm{n}=3$ \\
$\mathrm{I}_{50}$ AMP & $34.7 \pm 0.52$ & $49.2 \pm 1.38^{\mathrm{a}}$ & $<0.005, \mathrm{n}=3$ \\
$\mathrm{I}_{50}$ ATP & $3.52 \pm 0.07$ & $3.53 \pm 0.09$ & $\mathrm{NS}, \mathrm{n}=3$ \\
$\mathrm{I}_{50}$ alanine & $59.5 \pm 7.3$ & $44.0 \pm 0.9$ & $\mathrm{NS}, \mathrm{n}=3$ \\
$\mathrm{I}_{50}$ glycerol-3-phosphate & $61.5 \pm 2.1$ & $73.1 \pm 1.3^{\mathrm{a}}$ & $<0.05, \mathrm{n}=3$ \\
$\mathrm{I}_{50}$ glucose & $81.3 \pm 1.9$ & $91.6 \pm 1.7$ & $\mathrm{NS}, \mathrm{n}=3$ \\
$\mathrm{I}_{50} \mathrm{H}_{2} \mathrm{O}_{2}$ & $10.1 \pm 1.39$ & $10.7 \pm 0.23$ & $\mathrm{NS}, \mathrm{n}=3$ \\
$\mathrm{I}_{50}$ sodium sulfate & $11.5 \pm 0.19$ & $11.0 \pm 0.19$ & $\mathrm{NS}, \mathrm{n}=3$ \\
$\mathrm{I}_{50}$ potassium oxalate monohydrate & $0.317 \pm 0.010$ & $0.301 \pm 0.008$ & $\mathrm{NS}, \mathrm{n}=3$ \\
$\mathrm{I}_{50}$ cysteine & $12.4 \pm 0.89$ & $13.1 \pm 1.11$ & $\mathrm{NS}, \mathrm{n}=3$ \\
\hline
\end{tabular}


Table 2.3. Effect of sugars and an amino acid on the affinity constant for PEP of PK from gall fly larvae. All assays were carried out at room temperature $\left(22^{\circ} \mathrm{C}\right)$ and $\mathrm{pH} 7.2$ in the presence of additives as shown in the table. Data are means \pm SEM, $n=3$. Statistical testing used ANOVA followed by a Tukey post-hoc test. ${ }^{\text {a }}$ - significantly different from the corresponding control value in the presence of the same additive using one-way ANOVA, $\mathrm{p}<0.01 ;{ }^{\mathrm{b}}$-significantly different from the corresponding value without an additive using one-way ANOVA, $\mathrm{p}<0.01$.

\begin{tabular}{lll}
\hline Affinity Constant (mM) & Control & Frozen \\
\hline $\mathrm{K}_{\mathrm{m}}$ PEP, pH 7.2 & $0.126 \pm 0.005$ & $0.150 \pm 0.003^{\mathrm{a}}$ \\
$\mathrm{K}_{\mathrm{m}}$ PEP, 5 mM L-alanine & $0.066 \pm 0.013^{\mathrm{b}}$ & $0.098 \pm 0.009^{\mathrm{a}, \mathrm{b}}$ \\
$\mathrm{K}_{\mathrm{m}}$ PEP, 30 mM glucose & $0.136 \pm 0.006$ & $0.134 \pm 0.010$ \\
$\mathrm{~K}_{\mathrm{m}}$ PEP, 2.5 mM glycerol-3-phosphate & $0.064 \pm 0.005^{\mathrm{b}}$ & $0.084 \pm 0.009^{\mathrm{b}}$ \\
$\mathrm{K}_{\mathrm{m}}$ PEP, 52.5 mM glycerol-3-phosphate & $0.134 \pm 0.012$ & $0.154 \pm 0.014$ \\
\hline
\end{tabular}




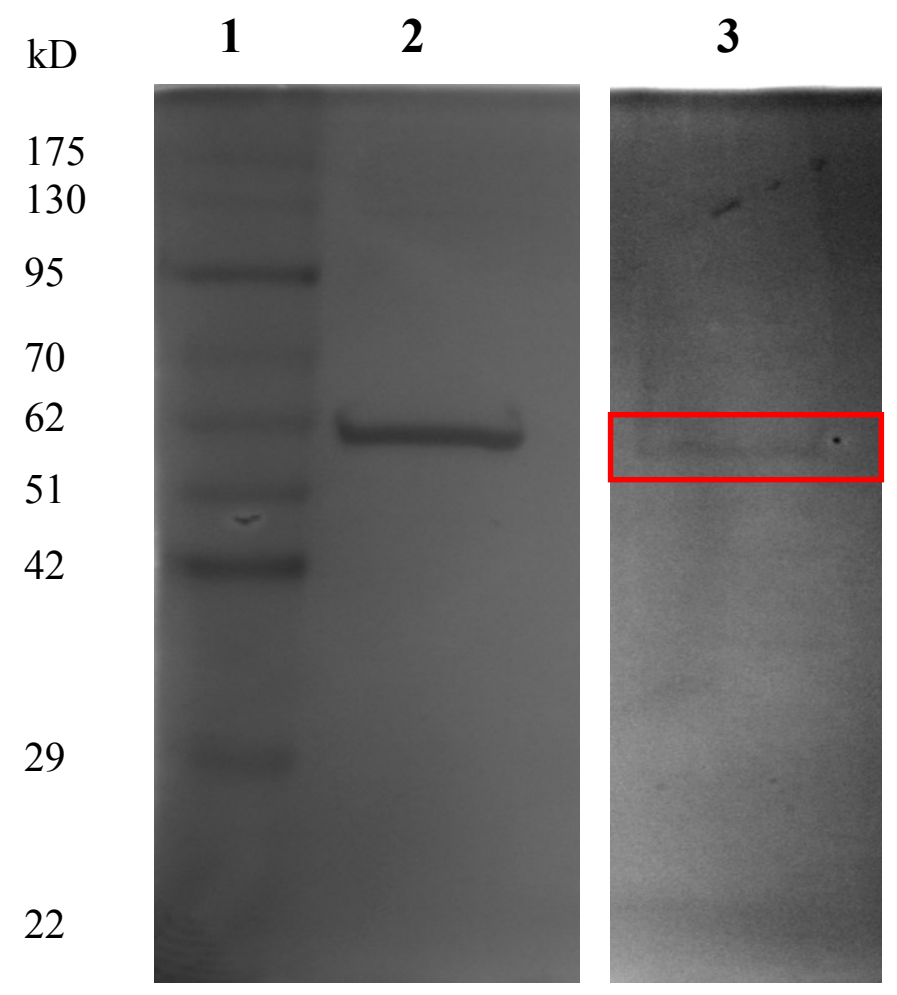

Figure 2.1. SDS-PAGE gel showing the purification of PK from control gall flies. Lanes are: (1) Genedirex 10.5-175 kD protein ladder, (2) PK from Lactobacillus leichmanii (Sigma), and (3) purified PK from control gall flies. The gel was stained with silver. 


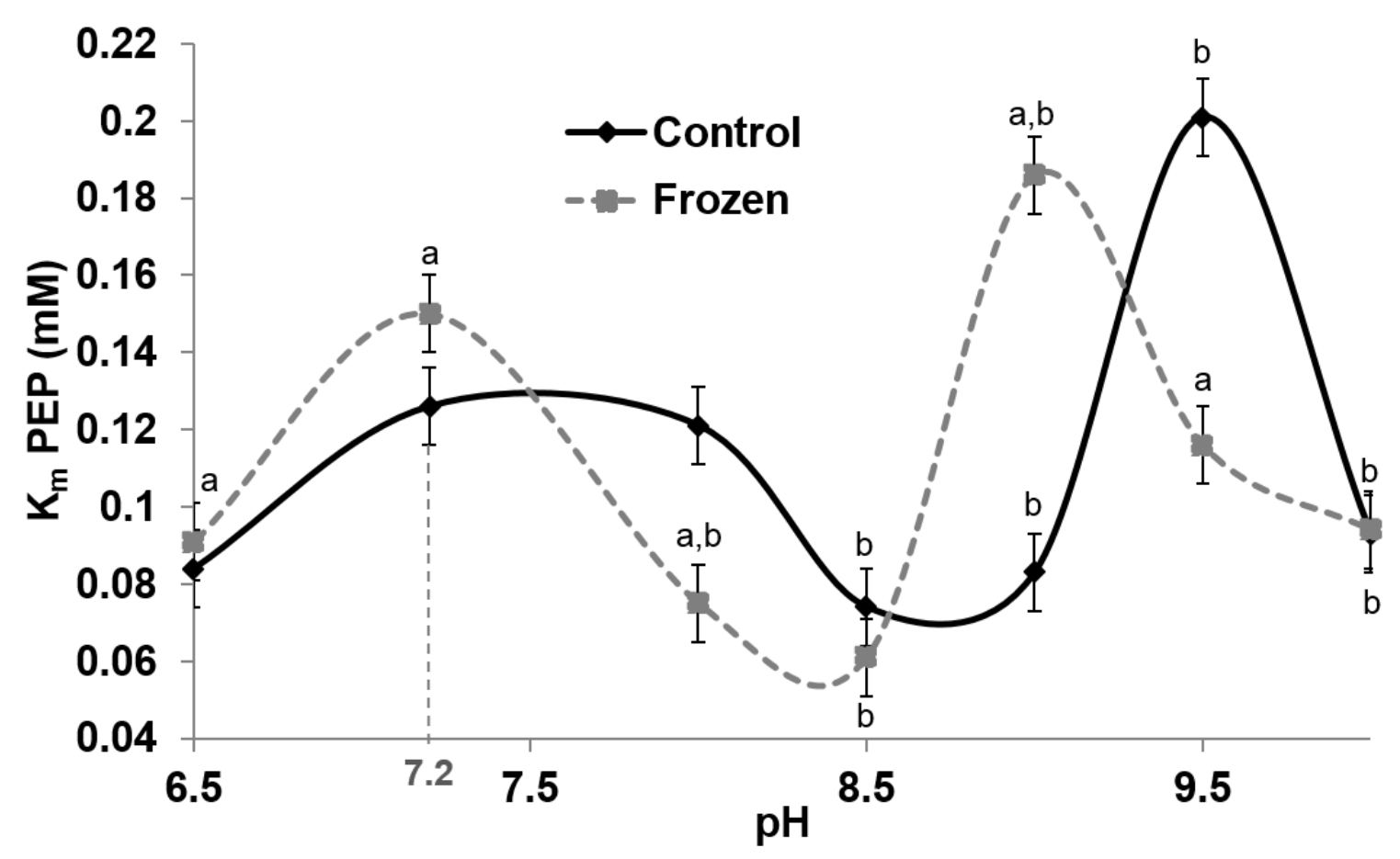

Figure 2.2. The effect of $\mathrm{pH}$ on the $\mathrm{K}_{\mathrm{m}} \mathrm{PEP}$ of $\mathrm{PK}$ from control and frozen gall flies.

Data are means \pm SEM, $n=3$. Statistical testing used ANOVA followed by a Tukey posthoc test. ${ }^{\mathrm{a}}$ - significantly different from the corresponding control value at the same $\mathrm{pH}$, $\mathrm{p}<0.01 ;{ }^{b}$-significantly different from the corresponding value at the optimum $\mathrm{pH}$ of 7.2 , $\mathrm{p}<0.01$ 

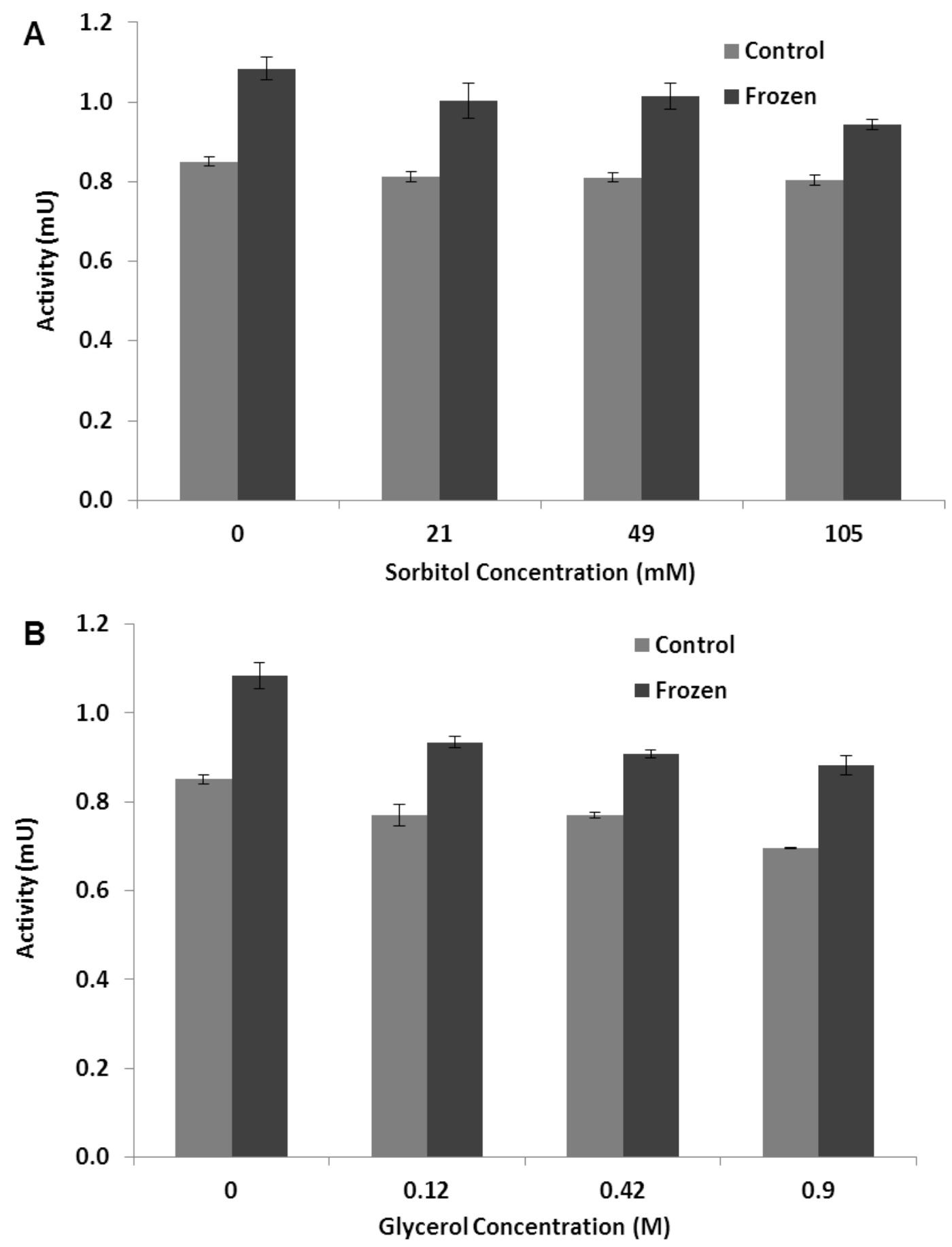

Figure 2.3. Activity of PK from control and frozen gall fly larvae in the presence of the natural cryoprotectants accumulated by the insects: sorbitol (A) and glycerol (B). Activity was determined at sub-optimal concentrations of both substrates, $0.5 \mathrm{mM}$ PEP or $1 \mathrm{mM}$ ADP. Data are means \pm SEM, $n=3$. 


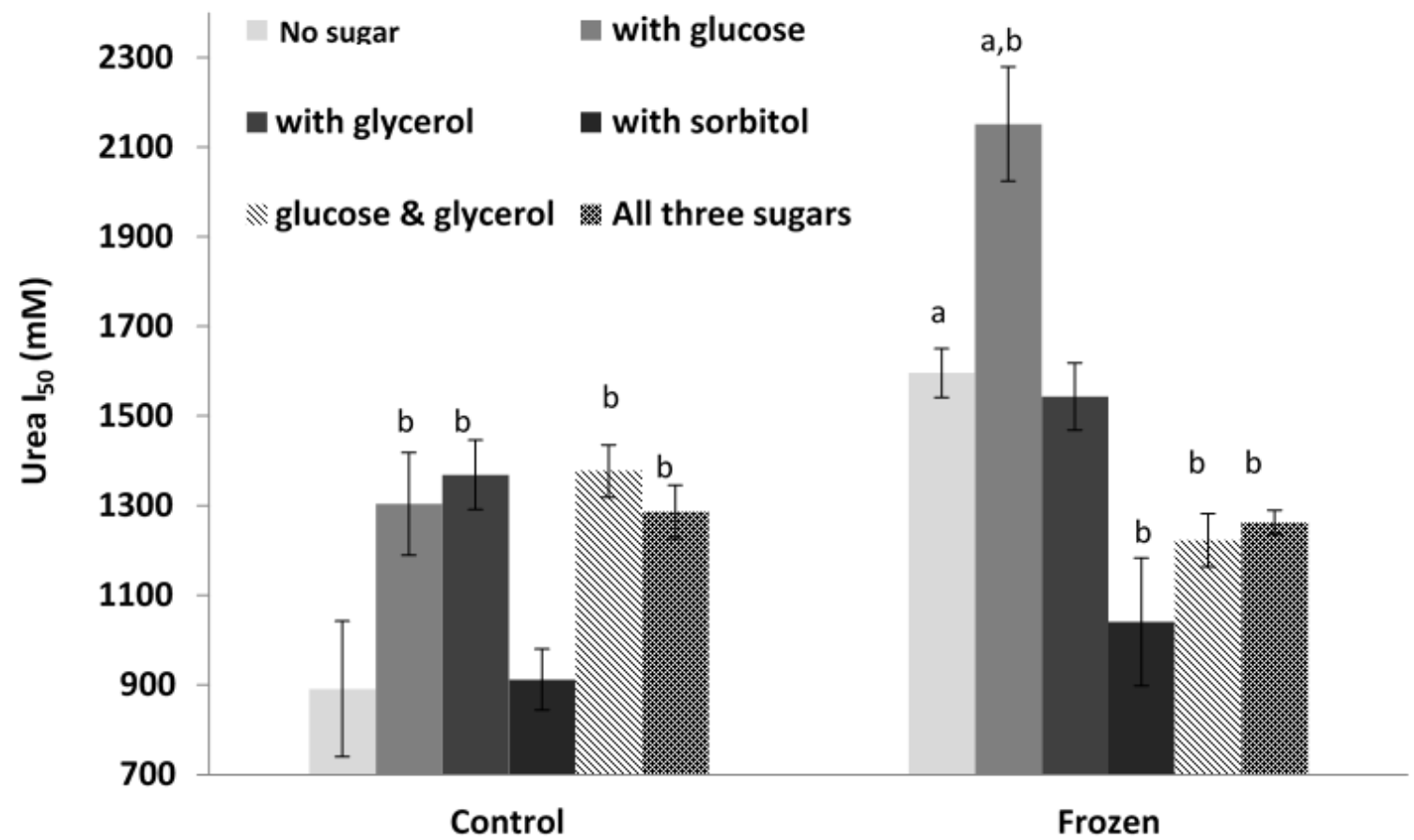

Figure 2.4. The effect of adding sugars on the $I_{50}$ value for urea of PK purified from control and frozen gall fly larvae. The sugar concentrations used were: $30 \mathrm{mM}$ glucose, $240 \mathrm{mM}$ glycerol, and $81 \mathrm{mM}$ sorbitol. Data are means \pm SEM, $\mathrm{n}=4$. Statistical testing used ANOVA followed by a Tukey post-hoc test. ${ }^{\text {a }}$ - significantly different from the corresponding control value in the presence of the same additive, $\mathrm{p}<0.01 ;^{\mathrm{b}}$ - significantly different from the corresponding value without a sugar added, $\mathrm{p}<0.01$. 

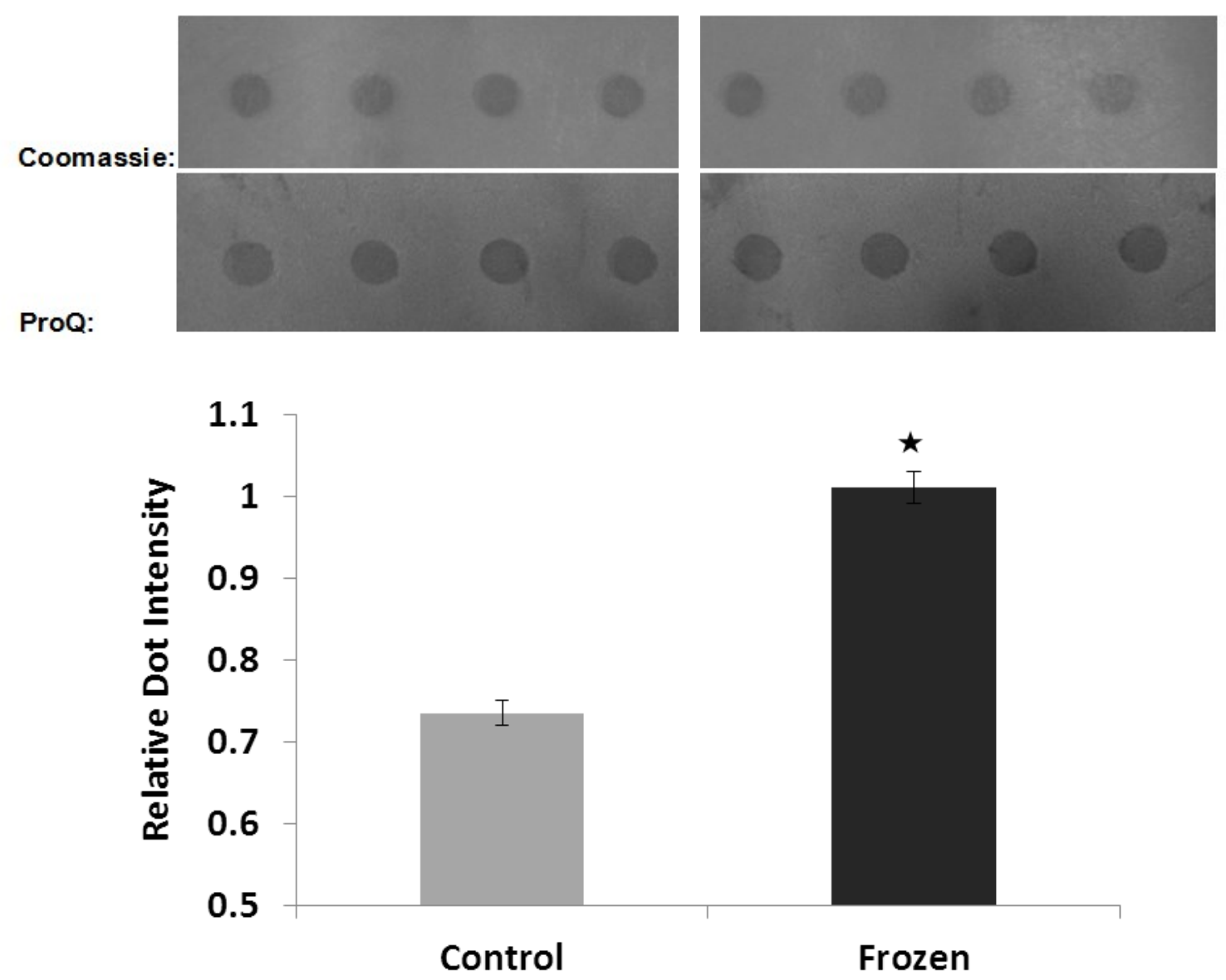

Figure 2.5. Dot blot showing Pro-Q Diamond phosphoprotein staining of PK (and corresponding Coomassie blue staining of the dots) and quantification of the relative phosphorylation on PK purified from control versus frozen gall fly larvae. Data are mean \pm SEM, $\mathrm{n}=4{ }^{*}{ }^{*}$ - significantly different from the control by the Student's t-test, $\mathrm{p}<0.05$. 


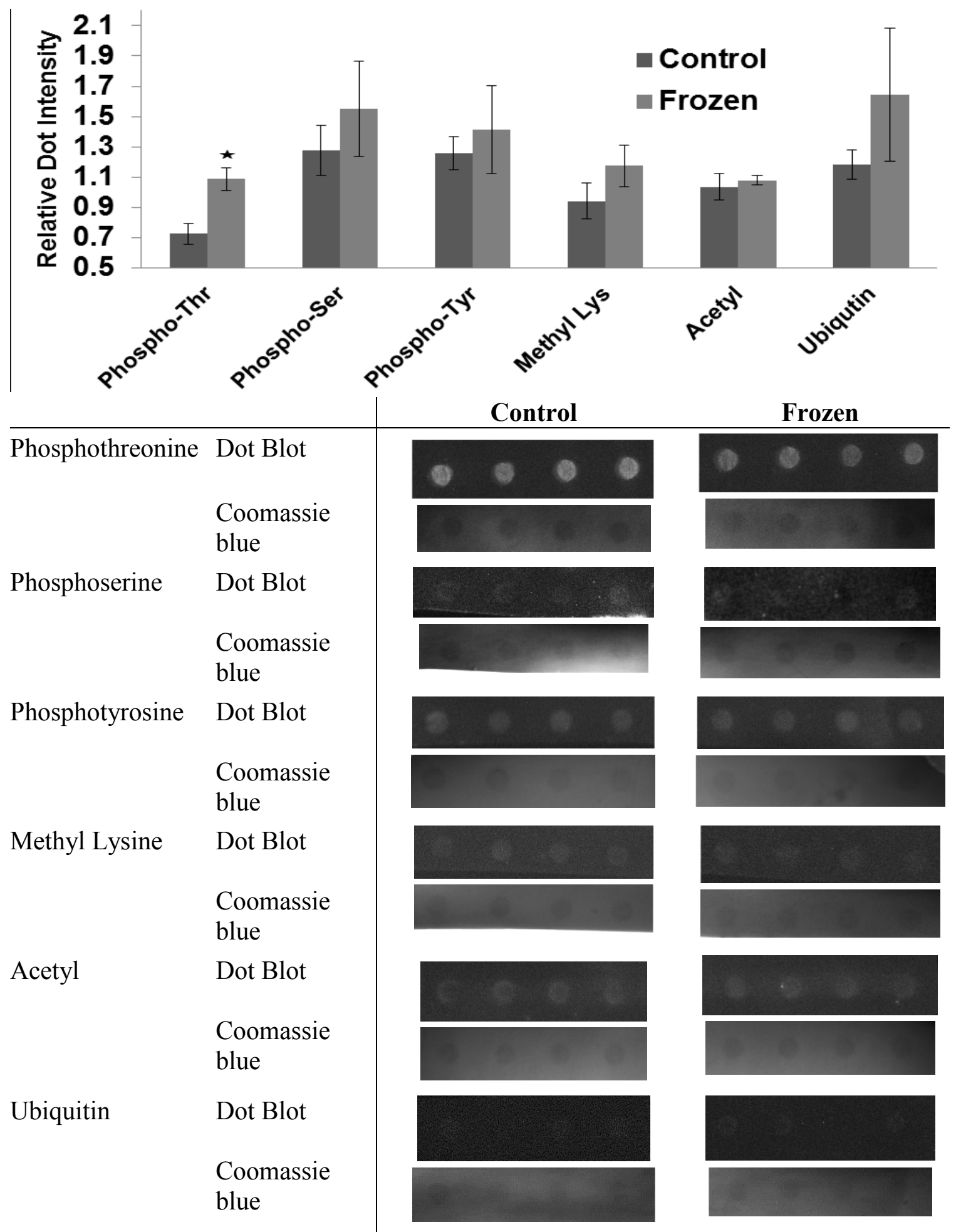

Figure 2.6. Dot blots with antibodies assessing different post-translational modifications and Coomassie protein staining of PK purified from control and frozen gall fly larvae. Data are mean \pm SEM, $n=8$ for phospho-threonine and $n=4$ for the rest. *significantly different from the corresponding control by the Student's t-test, $\mathrm{p}<0.05$. 


\section{Discussion}

While in the frozen state gall fly larvae must rely on anaerobic glycolysis for the generation of ATP since freezing cuts off oxygen delivery to cells, thereby inhibiting mitochondrial respiration and leading to the build-up of anaerobic end products (lactate, alanine) in the frozen state (Storey et al., 1981b). The larvae may be frozen for days, weeks or sometimes months at a time and a net depletion of energy reserves (arginine phosphate and ATP) occurs but these must also be sustained at minimum levels by glycolytic ATP production in order to maintain viability. PK is the last enzyme in glycolysis, one of the two ATP-generating steps in the pathway, and can be a point of control of the outward flow of carbon towards fates including lactate production, oxidation by mitochondria, and biosynthesis of many sorts. This investigation shows that PK from 5 and $-15^{\circ} \mathrm{C}$ acclimated gall fly larvae demonstrated prominently different kinetic properties, structural stability, and different phosphorylation states.

The affinity of PK for its substrate, PEP, changed significantly in the frozen state as shown by a $\sim 20 \%$ increase in $\mathrm{K}_{\mathrm{m}}$ PEP, which causes catalytic efficiency to decrease. Although there was a similar total PK activity in both control and frozen states when assayed under optimal conditions, the reduction in substrate affinity may suggest a different result in vivo where PEP concentrations are low. In the desert snail, Otala lactea, the $\mathrm{K}_{\mathrm{m}}$ PEP was found to increase as a result of an increase in relative protein phosphorylation by endogenous kinases when the snails entered estivation and experienced anoxia (Whitwam and Storey, 1990). Furthermore, the I50 values for MgATP and L-alanine were reduced for the phosphorylated form of $O$. lactea PK, which indicates greater inhibition by these metabolites, all pointing towards a reduction in PK 
activity in the stress-induced hypometabolic state. Therefore, while there was no change observed in alanine or ATP inhibition with gall fly PK, the evidence thus far suggests that a hypometabolic state may be the goal of PK regulation.

In addition to direct changes in substrate affinity, $\mathrm{PK}$ is regulated via effectors such as activators and inhibitors. A commonly documented PK activator is fructose-1,6bisphosphate (FBP) but it was not found to activate gall fly PK. Among the numerous PK inhibitors, alanine and Mg-ATP were found to change potency when the host experienced stress (Plaxton and Storey 1984a; Whitwam and Storey, 1990; Michaelidis and Storey, 1990; Greenway and Storey, 2000). For example, in foot muscle of the whelk, Busycon canaliculatum, the $\mathrm{I}_{50}$ values for Mg-ATP and alanine decreased under anoxic conditions and responded differently to assay temperature and $\mathrm{pH}$ (Michaelidis and Storey, 1990). In the gall fly, no changes in $\mathrm{I}_{50}$ values for ATP and alanine inhibition were observed. Additionally, the $\mathrm{I}_{50}$ ATP $(\sim 3.5 \mathrm{mM})$ was found to be much lower than whelk Mg-ATP inhibition. Similarly, the I50 AMP was roughly 500-fold higher than physiological AMP levels, however, it did show a large change in frozen PK (Table 2.2). Along with a similar trend in $\mathrm{I}_{50} \mathrm{G} 3 \mathrm{P}$ (Table 2.2) and the rest of the inhibition data, it is clear that the gall fly does not rely on any form of inhibition to regulate PK during freezing.

Since alanine, G3P, and glucose all increase in frozen gall fly larvae, their effects on the substrate affinity of PK were measured. The levels of alanine (5 mM) and G3P $(2.5 \mathrm{mM})$ that are physiological at subzero temperatures in the gall fly were found to lower the $\mathrm{K}_{\mathrm{m}}$ PEP by $\sim 50 \%$ in both control and frozen samples (Table 2.3). Physiological levels of glucose had no effect and neither did high levels of G3P (52.5 mM). These effects suggest a maintenance of PK activity under freezing conditions. However, the $\mathrm{K}_{\mathrm{m}}$ 
PEP was still significantly higher for the enzyme from frozen insects $(\sim 0.1 \mathrm{mM})$ in the presence of alanine as compared to the control value $(\sim 0.07 \mathrm{mM}$; Table 2.3$)$. Additionally, $\mathrm{pH}$ could play a big role in these kinetic changes because $\mathrm{pH}$ rises as temperature is reduced and this may change the way that PK responds to effectors. In the previously mentioned study on the whelk, the properties of PK were found to be less altered when the assay $\mathrm{pH}$ was allowed to rise to 7.25 from 7.00 with a temperature decrease from $20^{\circ} \mathrm{C}$ to $5^{\circ} \mathrm{C}$ (Michaelidis and Storey, 1990). In this study, the effect of $\mathrm{pH}$ on PEP affinity was measured and compared between control and frozen PK. Both enzyme forms showed a double peak pattern with the first peak being around neutral $\mathrm{pH}$ and the second being between $\mathrm{pH}$ 9-9.5 (Figure 2.2). However, frozen PK showed a distinct left-ward shift (towards the acid end) of the $\mathrm{K}_{\mathrm{m}}$ PEP compared to control. As a result, there was a pronounced difference in the $\mathrm{PK} \mathrm{K}_{\mathrm{m}}$ values for control vs frozen larvae at $\mathrm{pH} 8,9$ and 9.5 (Figure 2.2). To interpret the results, we have to consider that the intracellular $\mathrm{pH}$ rises in the gall fly at lower temperatures based on the findings of numerous studies (Heisler et al., 1976; Malan et al., 1976; Reeves, 1972; Reeves and Malan, 1976; Michaelidis and Storey, 1990, Storey et al., 1984). While it can be argued that under anaerobic conditions $\mathrm{pH}$ becomes more acidic because of a build-up of lactic acid, we have already established that in the gall fly lactate reaches a plateau as temperature drops and does not reach high levels (Storey and Storey, 1985). Therefore, if the intracellular $\mathrm{pH}$ in gall fly rises slightly in freezing conditions ( pH 7.5), PEP affinity will equalize to control, but if it increases even higher ( $\mathrm{pH}$ 8), frozen PK would have a much higher PEP affinity than control (Figure 2.2). Furthermore, if the $\mathrm{pH}$ were to rise to 9 (highly unlikely), then the reverse effect would be observed and frozen PK would have 
a much lower affinity for PEP (Figure 2.2). Since gall fly larvae experience temperatures well below $-15^{\circ} \mathrm{C}$ while maintaining lactate levels at or below $3.39 \mu \mathrm{mol} / \mathrm{g}$ wet wt., it is more likely that their intracellular $\mathrm{pH}$ increases rather than decreases (Storey and Storey, 1985). Therefore, based on all the evidence, under basic conditions and in the presence of alanine and G3P frozen PK activity is being maintained despite a hypometabolic state. However, pyruvate levels do not change in gall fly larvae acclimated to a range of temperatures from 15 to $-30^{\circ} \mathrm{C}$ (Storey et al., 1981b). Therefore, there is much left to be understood on the regulation of PK in the gall fly.

There are factors other than direct kinetic properties that can play a role in enzyme regulation such as protein structure and stability. Polyol cryoprotectants are involved in such a role because in addition to protecting against freezing and dehydration, they also act to stabilize the native state of proteins to prevent denaturation due to low temperature or freezing (Storey et al., 1991). For this reason, the effects on the activity of PK of the two most abundant cryoprotectants in the gall fly were measured. Concentrations of glycerol and sorbitol ranging from below to above their peak concentrations in frozen gall fly larvae in vivo had no effect on the activity of either control or frozen PK (Figure 2.3). However, to further investigate the potential stabilization of PK by gall fly cryoprotectants, the denaturation of PK by urea was assessed in the presence of glycerol, sorbitol and glucose. It was important to note that without any additives, frozen PK showed a higher stability based on a significantly greater $I_{50}$ urea (Figure 2.4). Glucose alone significantly increased the $I_{50}$ urea of both control and frozen PK to a similar degree while sorbitol alone actually decreased the $\mathrm{I}_{50}$ urea of frozen PK (Figure 2.4). However, glycerol at high levels had no effect on the $\mathrm{I}_{50}$ 
urea of frozen PK while increasing the $\mathrm{I}_{50}$ urea of control PK to a value similar to that seen in the presence of high glucose. Interestingly, combinations of the sugars (glucose and glycerol, or all three) equally decreased the stability of frozen PK while also increasing the $\mathrm{I}_{50}$ urea of control PK to a value similar to that of glucose alone (Figure 2.4). Based on this data and the fact that all three sugars are present in frozen gall fly larvae, it is clear that the structural stability of frozen PK is compromised in the presence of these cryoprotectants but not to the point of the inferior stability of control PK.

To explain the different kinetic and structural properties of gall fly PK, a common regulatory mechanism was examined. Reversible PTMs have been shown to act as an onoff switch or regulators of protein activity based on many studies (Storey and Storey, 2007). PTMs affecting E. solidaginis PK were examined using both Pro-Q Diamond phosphoprotein staining and immunoblotting. Dot blots exposed to Pro-Q Diamond phosphoprotein staining showed a $\sim 30 \%$ greater relative protein phosphorylation for frozen PK as compared with the control enzyme (Figure 2.5). Immunoblotting indicated that this difference was the result of a significantly greater phosphothreonine content of the frozen enzyme (Figure 2.6). Similar results from other species are consistent with a stress-induced "high phosphate" form of PK that shows altered kinetic properties as compared with the control form (Plaxton and Storey, 1984b; Whitwam and Storey, 1990) although in some species environmental stress triggered the conversion of PK from a high phosphate to a low phosphate form (Cowan and Storey, 1999; Greenway and Storey, 2000). In all these studies, however, stress-induced changes in the phosphorylation state of PK had a similar effect of lowering activity to support a hypometabolic state. A similar example exists in the gall fly; freezing induced the suppression of activities of ion motive 
ATPases by reversible phosphorylation (McMullen and Storey 2008, 2010). Therefore, it is evident that PK has at least two forms in the gall fly; the "low phosphate" warm season form and the "high phosphate" cold season form. This is the most plausible explanation to the different kinetic and structural properties that were observed between warm and cold acclimated gall fly larvae.

The metabolic rate of diapausing gall fly larvae in midwinter was just $35 \%-40 \%$ of the early-autumn value at the same temperature (Irwin and Lee 2002; Levin et al. 2003). Taking this into consideration along with the previously mentioned fact that lipid oxidation and mitochondrial activity are halted in frozen gall fly, it is obvious that at least a basal activity of glycolysis must be maintained to support cell energy needs. PK regulation is an important component of this glycolytic control. We have seen that PK from frozen insects has a lower substrate affinity in vitro but a number of factors increased affinity including allosteric effects by alanine and G3P, as well as changes in $\mathrm{pH}$. Additionally, the high phosphate form of PK showed greater protein stability but a different interaction with the cryoprotectants, namely, a reduction in stability (in the presence of glycerol, sorbitol and glucose) that still is more stable than the low phosphate form. Winter presents gall fly larvae with a number of environmental changes that affect cell function and it appears that the structural changes brought about by phosphorylation allow PK to maintain its activity at a lower basal metabolic rate that contributes to sustaining glycolytic ATP production in the frozen state. 


\section{Chapter 3: \\ Glycerol-3-phosphate dehydrogenase in the goldenrod gall fly}




\section{Introduction}

Gall fly larvae not only need to survive the winter but also need to have enough lipid and protein to pupate into fertile adults. It has been shown that their total body lipid and protein content does not decrease during the winter (Storey and Storey, 1986). Additionally, lipid was not used as a substrate by mitochondria from cold-acclimated larvae when mitochondrial respiration was assayed at $1{ }^{\circ} \mathrm{C}$ (Ballantyne and Storey, 1985). Another survival strategy employed by gall fly larvae is the accumulation of large amounts of glycogen prior to entering diapause. Levels increased 9-fold in early autumn and this glycogen, although largely used to support cryoprotectant synthesis during the autumn, also provides an alternative fuel source for both winter energy production and spring resumption of development (Storey and Storey, 1986). Indeed, glycogen and/or glucose is a crucial fuel for when larvae are frozen since anaerobic glycolysis is the only source of ATP production in the frozen, anoxic state. Therefore, all these strategies contribute towards giving the gall fly the ability to survive through the winter and have sufficient fuel reserves to pupate, metamorphose to the adult stage, and successfully reproduce.

The enzymes involved in producing glycerol divert triose phosphates out from the glycolytic pathway. Of the two possible glycerol-producing pathways, the current chapter focuses on the one that uses DHAP as a substrate (the other pathway starts with GAP; Joanisse and Storey, 1994). Instead of DHAP being converted to GAP in glycolysis, it is converted to G3P by G3PDH and then to glycerol by glycerol-3-phosphatase. This was confirmed as a major source of glycerol production because there is a rise in G3P (indicating an inhibition of G3P dephosphorylation) after glycerol accumulation stops 
(Storey and Storey, 1982). The production of G3P can also be used by the gall fly to synthesize lipids and to build triglyceride reserves for fuel during the nonfeeding adult stage (Storey and Storey, 1982). A previous study by our laboratory found no change in $\mathrm{G} 3 \mathrm{PDH}$ activity from gall fly larvae acclimated to temperatures of $15^{\circ}$ versus $-30^{\circ} \mathrm{C}$ (Storey and Storey, 1981) and neither were there any changes in the levels of G3PDH effectors (Storey et al., 1981b). High levels of sorbitol and glycerol increased the thermal stability of G3PDH, which could also help its stability at low temperatures. Interestingly, the stabilization effect that sorbitol and glycerol have on gall fly G3PDH was greater than that on rabbit G3PDH, suggesting a regulatory mechanism (Storey and Storey, 1982). All these taken into consideration, G3PDH is of great interest as a regulatory locus in metabolism that influences the winter survival of gall fly larvae.

To the best of my knowledge, there have not been any reports of G3PDH being reversibly post-translationally modified in response to a stimulus such as environmental stress. There are reports, however, of changes in kinetic parameters such as in the liver and skeletal muscle of hibernating black-tailed prairie dogs, Cynomys ludivicianus (de la Roche et al., 2012). The substrate affinity $\left(\mathrm{K}_{\mathrm{m}}\right)$ for DHAP of prairie dog muscle G3PDH decreased by almost $50 \%$ under $5^{\circ} \mathrm{C}$ assay conditions compared to $22^{\circ} \mathrm{C}$. Similarly, the $\mathrm{K}_{\mathrm{m}} \mathrm{NADH}$ was three times lower at $5^{\circ} \mathrm{C}$ for prairie dog muscle G3PDH (de la Roche et al., 2012). The present study analyzes purified G3PDH from goldenrod gall fly larvae, evaluating the effects of whole animal freezing exposures on G3PDH properties and assessing the potential involvement of different PTMs as a regulatory mechanism. 


\section{Methods}

\section{Chemicals and Animals}

Chemical purchases, animal collection and procedures was as described in Chapter 2.

\section{Preparation of tissue extracts and enzyme purification}

Samples of frozen insects (E. solidaginis) were homogenized and centrifuged as described in Chapter 2 but in buffer $\mathrm{C}$ instead $(10 \mathrm{mM}$ Tris buffer, $\mathrm{pH} 8.0,10 \% \mathrm{v} / \mathrm{v}$ glycerol, 5 mM 2-mercaptoethanol, 1.5 mM EDTA, 1.5 mM EGTA, 25 mM $\beta$ glycerophosphate) with PMSF added immediately before homogenization. After centrifugation, a $2 \mathrm{~mL}$ aliquot of supernatant was diluted 1:2 $\mathrm{v}: \mathrm{v}$ in buffer $\mathrm{C}$ and loaded onto a $5 \times 1 \mathrm{~cm}$ column of Cibacron blue column (bead bed at $1 \mathrm{~cm}$ from bottom) equilibrated in buffer $\mathrm{C}$, washed to remove unbound protein and eluted with $30 \mathrm{~mL}$ of buffer $\mathrm{C}$ containing $1 \mathrm{M} \mathrm{KCl}$. Interference due to low molecular weight metabolites and ions was found to inhibit binding of G3PDH to the subsequent column. To remove these, $5 \mathrm{~cm}$ columns of Sephadex G-25 were prepared in syringe barrels, equilibrated in buffer $\mathrm{C}$ and centrifuged at $1,500 \mathrm{rpm}$ in a bench-top centrifuge for $3 \mathrm{~min}$ to remove excess liquid. The eluent from the previous step with highest enzyme activity was then applied to the columns (a maximum $500 \mu \mathrm{L}$ aliquot per column) and centrifuged again. The eluent from all columns was pooled and applied to a second Cibacron blue column equilibrated in buffer $\mathrm{C}$, washed and eluted with a gradient of 2:2 mM NADH:G3P in buffer C. To remove these substrates, the previous Sephadex G-25 procedure was 
repeated. Purity of G3PDH was verified as described in Chapter 2. Purified G3PDH was collected for enzyme assay and a portion was kept for dot blot analysis.

\section{Enzyme assays}

G3PDH activity was measured by monitoring the production of NADH. The reaction was monitored at $340 \mathrm{~nm}$ using a Multiskan Spectrum microplate reader. Optimal assay conditions for the reverse reaction were determined to be $50 \mathrm{mM}$ Tris $\mathrm{pH}$ 8.6, $2 \mathrm{mM} \mathrm{NAD}^{+}$, and $10 \mathrm{mM} \mathrm{G} 3 \mathrm{P}$ in a $200 \mu \mathrm{L}$ total volume; assays were typically started by the addition of $20 \mu \mathrm{L}$ of purified enzyme. Routine assays were run at room temperature $\left(22^{\circ} \mathrm{C}\right)$. $\mathrm{I}_{50}$ for urea was determined at constant, subsaturating levels of substrate, $5 \mathrm{mM} \mathrm{G3P}$ or $1.5 \mathrm{mM} \mathrm{NAD}^{+}$.

Dot blots

Dot blots were carried out as described in Chapter 2.

\section{Data and Statistical Analysis}

These procedures were carried out as described in Chapter 2.

\section{Mass Spectrometry}

To confirm the identity of the enzyme being used in this study, a sample of purified enzyme was sent to the Québec Genomics Center of the CHU de Québec Research Center (Québec, QC) for proteomic analysis by mass spectrometry. The purified enzyme preparation was run on SDS-PAGE as described in Chapter 2 and 
stained with Coomassie blue. The G3PDH band was identified based on molecular weight, and then it was cut out and destained. The gel sample was placed in $100 \mu \mathrm{L}$ of $\mathrm{ddH}_{2} \mathrm{O}$ and shipped in a $1.5 \mathrm{~mL}$ Eppendorf tube at room temperature. Data was viewed in Scaffold 4 Proteomics Software.

\section{Results}

Purification of $G 3 P D H$

G3PDH was purified from control $\left(5^{\circ} \mathrm{C}\right.$ acclimated $)$ and frozen $\left(-15^{\circ} \mathrm{C}\right.$ acclimated) gall fly larvae using a two-step method. The first purification step was a Cibacron blue column eluted with a $1 \mathrm{M} \mathrm{KCl} \mathrm{bump.} \mathrm{An} \mathrm{intermediate} \mathrm{step} \mathrm{was} \mathrm{then}$ required for removal of low molecular weight metabolites and ions by a Sephadex G-25 spun column before applying the enzyme to the next column. The second step was elution off a Cibacron blue column using a 2:2 mM NADH:G3P gradient. SDS-PAGE analysis showed single bands of G3PDH protein for all purified preparations; Figure 3.1 shows examples for purified G3PDH from frozen gall fly larvae. The calculated subunit molecular mass was $36.1 \pm 1.0 \mathrm{kD}$ ( $\mathrm{n}=3$ separate purifications), close to the value for commercially prepared G3PDH from rabbit muscle seen in lane 5.

Activities and kinetic analysis of purified G3PDH from control and frozen gall fly larvae

Table 3.1 shows kinetic parameters for G3PDH purified from control and frozen gall fly larvae. There was no significant difference in the $\mathrm{V}_{\max }$ of purified G3PDH (208$156 \mathrm{mU} / \mathrm{g}$ ) between the two insect states when assayed under optimal assay conditions at $\mathrm{pH} 8.6$ and $22^{\circ} \mathrm{C}$. However, the Michaelis constant $\left(\mathrm{K}_{\mathrm{m}}\right)$ for G3P differed significantly 
between control $(0.99 \pm 0.03 \mathrm{mM})$ and frozen $(1.36 \pm 0.03 \mathrm{mM})$ states $(\mathrm{p}<0.01, \mathrm{n}=4)$ but the $\mathrm{K}_{\mathrm{m}}$ value for $\mathrm{NAD}^{+}$did not differ. Inhibition of G3PDH by urea was the same for the enzyme from control and frozen larvae. Values for $\mathrm{I}_{50}$ were $3.51 \pm 0.08 \mathrm{M}$ for control and 3.41 $\pm 0.03 \mathrm{M}$ for frozen (Table 3.1).

The effect of sorbitol and glycerol, the sugars that accumulate as cryoprotectants in frozen gall fly larvae, were tested on the activity of G3PDH at $22^{\circ} \mathrm{C}$. Figure 3.2 shows that both sugars had no significant effect on G3PDH from control larvae at any concentration. Similarly, the sugars had no effect on G3PDH activity from frozen larvae except for glycerol at a concentration of $0.9 \mathrm{M}$ where activity was reduced significantly by $\sim 30 \%$. (Figure 3.2 ). The affinity constants for the G3PDH substrates of the reverse reaction, $\mathrm{G} 3 \mathrm{P}$ and $\mathrm{NAD}^{+}$, were measured and compared in the presence of the two principal cryoprotectants. The $\mathrm{K}_{\mathrm{m}} \mathrm{G} 3 \mathrm{P}$ was found to be significantly lower in control than frozen ( $\sim 37 \%$; Table 3.2). In the presence of $893 \mathrm{mM}$ glycerol, the $\mathrm{K}_{\mathrm{m}} \mathrm{G} 3 \mathrm{P}$ decreased significantly ( $\sim 50-60 \%)$ for the enzyme from both control and frozen larvae, and they remained different from each other (Table 3.2). In the presence of $106 \mathrm{mM}$ sorbitol, the $\mathrm{K}_{\mathrm{m}} \mathrm{G} 3 \mathrm{P}$ decreased strongly for the control enzyme to a value similar to that in the presence of glycerol. However, the $\mathrm{K}_{\mathrm{m}} \mathrm{G} 3 \mathrm{P}$ for the frozen enzyme did not decrease in the presence of sorbitol and instead actually increased slightly. The $\mathrm{K}_{\mathrm{m}} \mathrm{NAD}^{+}$was not significantly different between the enzyme from control and frozen states or in the presence/absence of glycerol or sorbitol (Table 3.2). 


\section{Structural Stability}

The effect of high concentrations of urea on the activity of G3PDH was assessed as a measure of the structural stability of the enzyme, urea being a known perturbant that causes enzyme unfolding (Table 3.3). There was no significant difference in the I50 value for urea between frozen and control enzymes. Glycerol $(315 \mathrm{mM})$, glucose $(30 \mathrm{mM})$ or both together had no significant effect on the $\mathrm{I}_{50}$ urea for G3PDH from control larvae (Table 3.3). By contrast, glycerol significantly increased the $\mathrm{I}_{50}$ urea (by $20 \%$ ) for frozen G3PDH as did the addition of both sugars together. Since glucose alone did not affect the $\mathrm{I}_{50}$ urea of frozen $\mathrm{G} 3 \mathrm{PDH}$, the effect of both sugars together is undoubtedly due to glycerol (Table 3.3).

\section{Dot blotting for post-translational modifications}

Selected potential post-translational modifications to gall fly G3PDH were assessed by dot blotting using purified preparations of enzyme from control and frozen larvae and antibodies that detected different PTMs on proteins. Dot intensities were standardized against the corresponding intensity of the same G3PDH dot after restaining with Coomassie blue. Standardized dot intensities showed significant differences between control and frozen conditions indicating changes in relative protein phosphorylation between the two states (Figure 3.3). Specifically, total serine phosphorylation was $61 \%$ lower, total threonine phosphorylation was $80 \%$ lower, and total tyrosine phosphorylation was $71 \%$ lower for G3PDH purified from frozen larvae as compared to the enzyme from control animals (Figure 3.3). Additionally, total protein ubiquitination was $56 \%$ lower for 
frozen G3PDH compared to control (Figure 3.3). However, there was no significant difference in relative protein acetylation between the two enzyme forms. 
Table 3.1. Kinetic parameters of purified G3PDH from control and frozen gall fly larvae. All assays were carried out at room temperature $\left(22^{\circ} \mathrm{C}\right)$ and $\mathrm{pH} 8.6 . \mathrm{K}_{\mathrm{m}}$ values were determined at optimal co-substrate concentration, either $10 \mathrm{mM} \mathrm{G3P}$ or 2 mM NAD. I50 values were determined at sub-optimal concentrations of both substrates, $5 \mathrm{mM} \mathrm{G} 3 \mathrm{P}$ or 1.5 mM NAD. Data are means \pm SEM, $n=3 .^{a}-$ Significantly different from the corresponding control value using the Student's test. NS - not significant.

\begin{tabular}{llll}
\hline Constants & Control & Frozen & P-value \\
\hline $\mathrm{V}_{\max }(\mathrm{mU} / \mathrm{g})$ & $208 \pm 20$ & $156 \pm 4$ & $\mathrm{NS}, \mathrm{n}=4$ \\
$\mathrm{~K}_{\mathrm{m}} \mathrm{G} 3 \mathrm{P}(\mathrm{mM})$ & $0.99 \pm 0.03$ & $1.36 \pm 0.03^{\mathrm{a}}$ & $<0.01, \mathrm{n}=4$ \\
$\mathrm{~K}_{\mathrm{m}} \mathrm{NAD}^{+}(\mathrm{mM})$ & $0.39 \pm 0.01$ & $0.36 \pm 0.03$ & $\mathrm{NS}, \mathrm{n}=4$ \\
$\mathrm{I}_{50}$ urea $(\mathrm{M})$ & $3.51 \pm 0.08$ & $3.41 \pm 0.03$ & $\mathrm{NS}, \mathrm{n}=3$ \\
\hline
\end{tabular}


Table 3.2. Interaction of substrate affinity with the presence of cryoprotectants (glycerol, sorbitol) for purified G3PDH from control and frozen gall fly larvae. Assays were carried out at room temperature $\left(22^{\circ} \mathrm{C}\right)$ and $\mathrm{pH} 8.6 . \mathrm{K}_{\mathrm{m}}$ values were determined at optimal cosubstrate concentration. Data are means \pm SEM, $n=4{ }^{a}$ - Significantly different from the corresponding control value using Student's test; ${ }^{b}$ - Significantly different from the same parameter measured in the absence of added sugar. NS - not significant.

\begin{tabular}{llll}
\hline Constants & Control & Frozen & P-value \\
\hline $\mathrm{K}_{\mathrm{m}} \mathrm{G} 3 \mathrm{P}$ & $0.99 \pm 0.03$ & $1.36 \pm 0.04^{\mathrm{a}}$ & $<0.001$ \\
$\mathrm{~K}_{\mathrm{m}} \mathrm{G} 3 \mathrm{P}, 893 \mathrm{mM}$ glycerol & $0.34 \pm 0.01^{\mathrm{b}}$ & $0.70 \pm 0.05^{\mathrm{a}, \mathrm{b}}$ & $<0.005$ \\
$\mathrm{~K}_{\mathrm{m}} \mathrm{G} 3 \mathrm{P}, 106 \mathrm{mM}$ sorbitol & $0.24 \pm 0.06^{\mathrm{b}}$ & $1.55 \pm 0.21^{\mathrm{a}}$ & $<0.005$ \\
$\mathrm{~K}_{\mathrm{m}} \mathrm{NAD}^{+}$ & $0.39 \pm 0.01$ & $0.36 \pm 0.02$ & $\mathrm{NS}$ \\
$\mathrm{K}_{\mathrm{m}} \mathrm{NAD}^{+}, 893 \mathrm{mM}$ glycerol & $0.31 \pm 0.08$ & $0.32 \pm 0.05$ & $\mathrm{NS}$ \\
$\mathrm{K}_{\mathrm{m}} \mathrm{NAD}^{+}, 106 \mathrm{mM}$ sorbitol & $0.30 \pm 0.07$ & $0.33 \pm 0.04$ & $\mathrm{NS}$ \\
\hline
\end{tabular}


Table 3.3. The effect of sugars on the $I_{50}$ urea of G3PDH from control and frozen gall fly larvae. Assays were carried out at room temperature $\left(22^{\circ} \mathrm{C}\right)$ and $\mathrm{pH} 8.6$ with sub-optimal substrate concentrations, $5 \mathrm{mM} \mathrm{G3P}$ and $1.5 \mathrm{mM}$ NAD. Data are means $\pm \mathrm{SEM}, \mathrm{n}=4$. Statistical testing used ANOVA followed by a Tukey post-hoc test. ${ }^{\text {a }}$ - significantly different from the corresponding control value in the presence of the same sugar, $p<0.01$; $\mathrm{b}$ - significantly different from the corresponding value without a sugar, $\mathrm{p}<0.01$.

\begin{tabular}{lll}
\hline I50 urea & Control & Frozen \\
\hline No sugar & $3.51 \pm 0.10$ & $3.41 \pm 0.04$ \\
Glycerol, $315 \mathrm{mM}$ & $3.94 \pm 0.07$ & $4.11 \pm 0.03^{\mathrm{b}}$ \\
Glucose, $30 \mathrm{mM}$ & $3.85 \pm 0.21$ & $3.47 \pm 0.03$ \\
Glycerol and Glucose & $3.83 \pm 0.11$ & $4.33 \pm 0.16^{\mathrm{a}, \mathrm{b}}$ \\
\hline
\end{tabular}




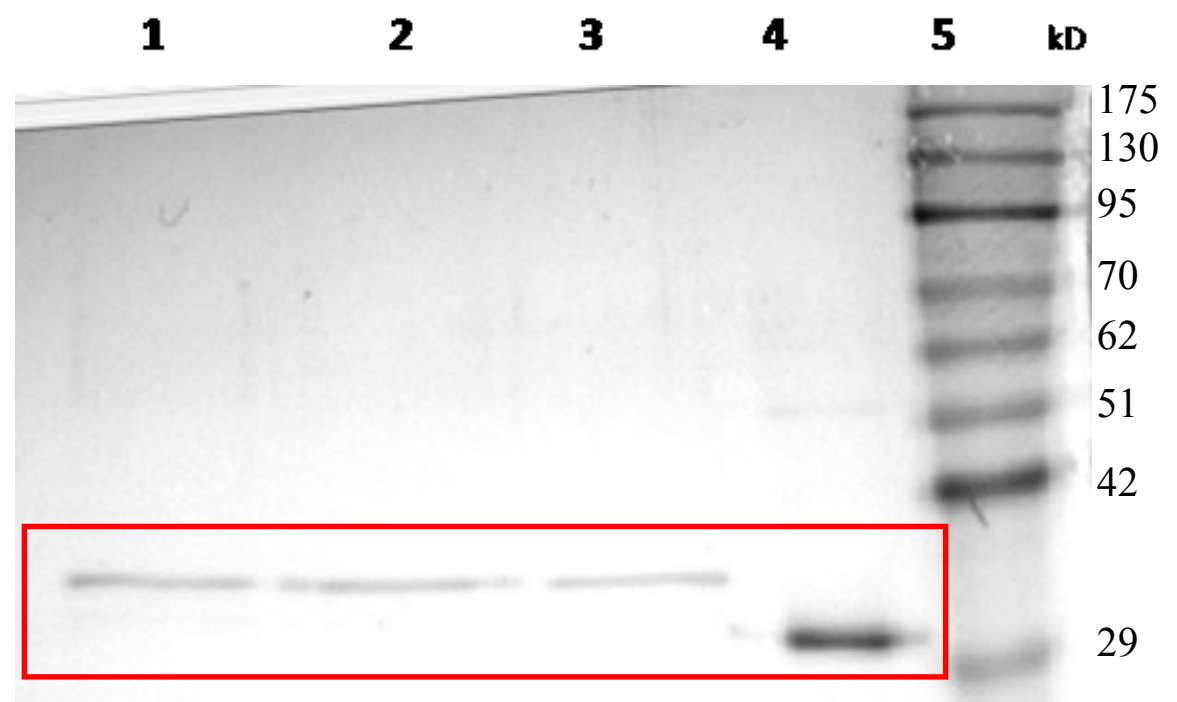

22

Figure 3.1. SDS-PAGE gel showing purification of G3PDH from gall fly larvae. Lanes are: (1-3) purified G3PDH from frozen larvae (G3PDH identity was confirmed by proteomic analysis by mass spectrometry), (4) commercial G3PDH from rabbit muscle (Sigma), (5) Genedirex 10.5-175 kD protein ladder. The gel was stained with Coomassie blue. 


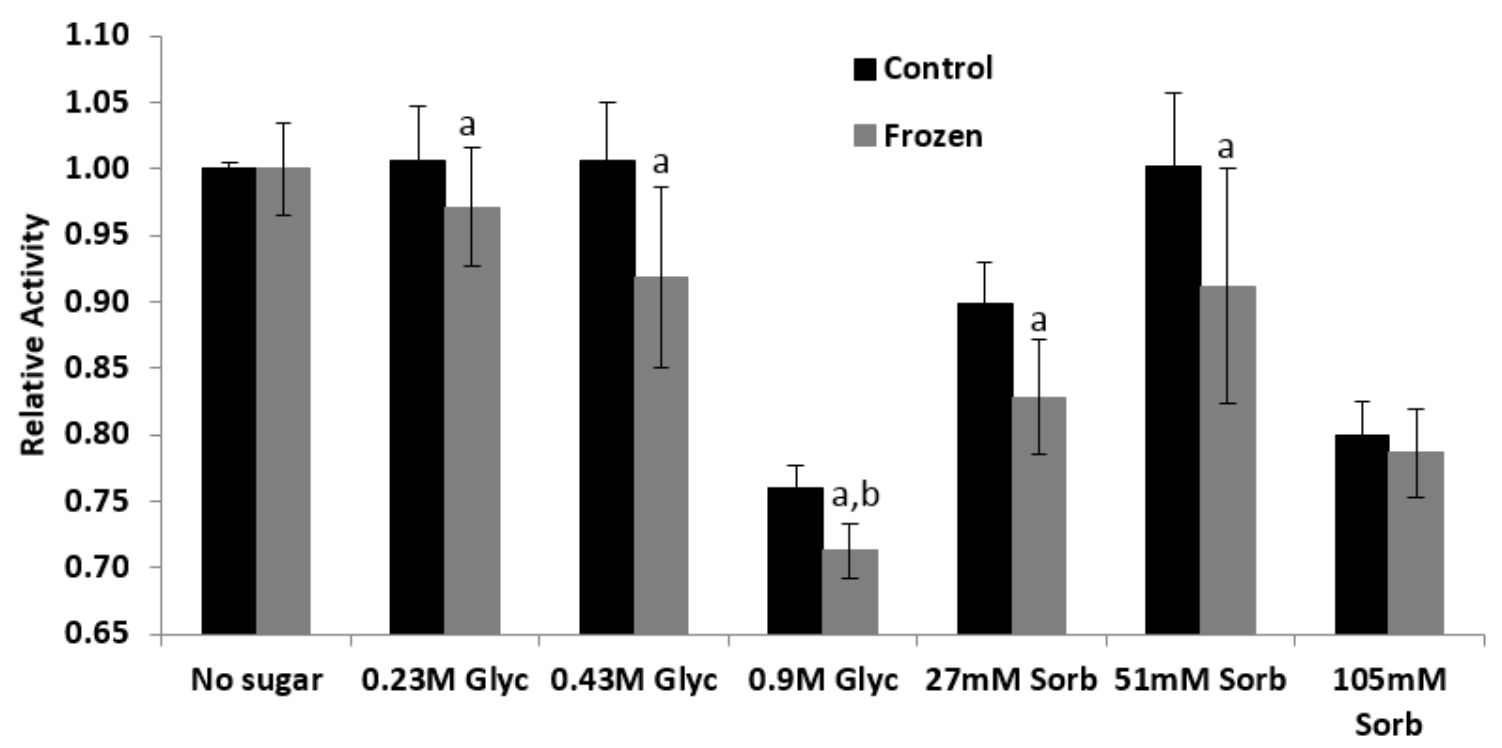

Figure 3.2. Relative activity of purified G3PDH from control and frozen gall fly larvae in the presence of different concentrations of cryoprotectants glycerol or sorbitol. Data are means \pm SEM, $n=3$. Statistical testing used ANOVA followed by a Tukey post-hoc test. a - significantly different from the corresponding control value in the presence of the same sugar, $\mathrm{p}<0.01 ;^{\mathrm{b}}$ - significantly different from the corresponding value without added sugar, $\mathrm{p}<0.01$. 


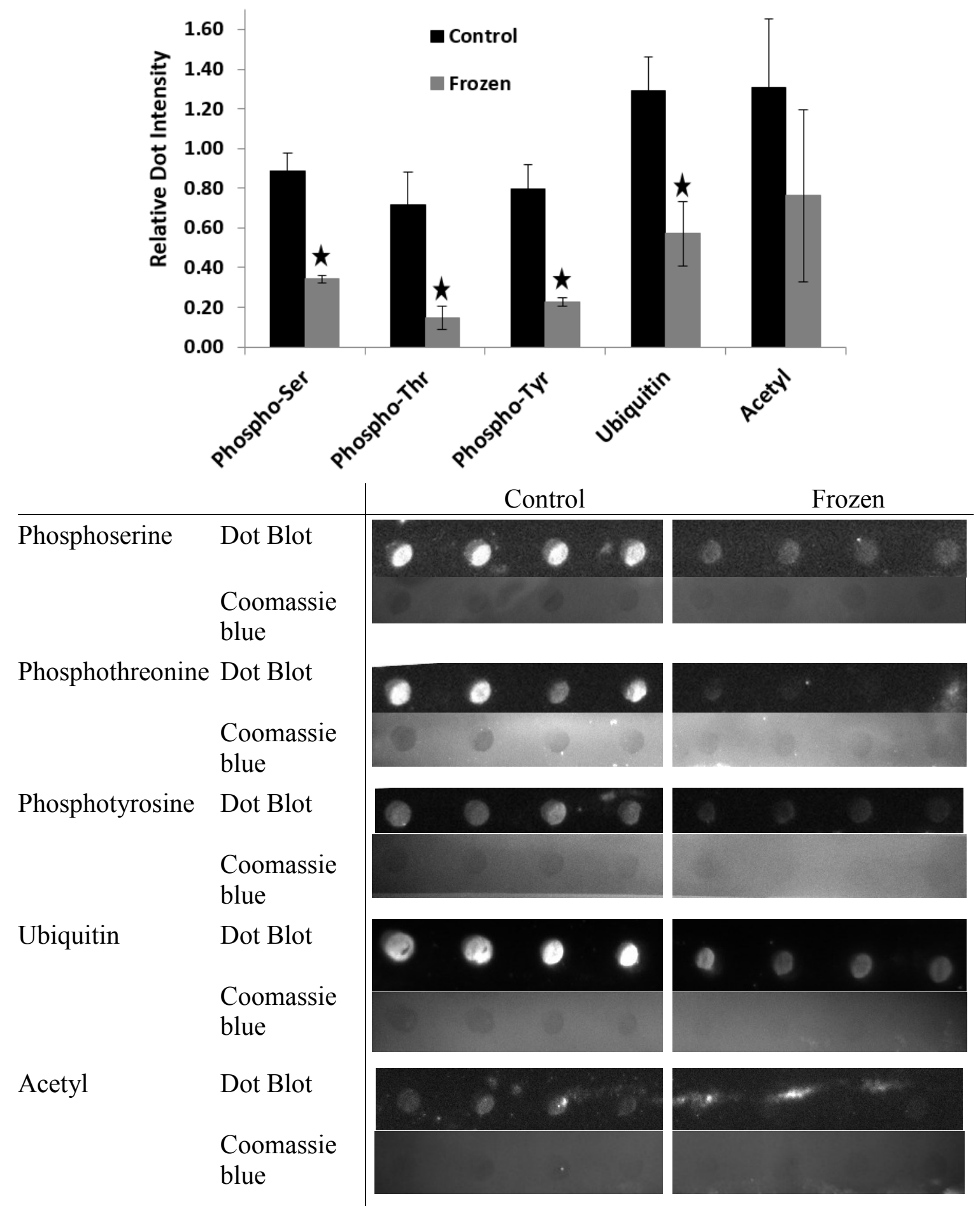

Figure 3.3. Dot blots with different PTM antibodies and Coomassie protein staining of G3PDH from control and frozen gall fly larvae. Data are mean $\pm \mathrm{SEM}, \mathrm{n}=4$. * significantly different by the Student's t-test, $\mathrm{p}<0.05$. 


\section{Discussion}

Instead of using any available fuel source during the winter, the gall fly elects to preserve its lipid and, to some extent, glycogen for post-season development. Because building up lipid storage requires a lot of food consumption, this is done during summer/autumn in preparation for the winter season and very little lipogenesis can take place in the frozen state because the energy and substrate requirements for lipid synthesis cannot be met without mitochondrial function. The same can be said for glycogen with the exception that a large proportion of it is converted into the cryoprotectants glycerol and sorbitol during the winter months (but reconverted in the spring). The timing of glycerol and sorbitol synthesis is very critical, which is why certain enzymes are regulated at specific temperatures. G3PDH is a locus of re-direction between three products; carbohydrates, triglycerides, and electron carriers. The gall fly produces high levels of glycerol over a few weeks as environmental temperatures start to decrease in the autumn and then switches to making NADPH-requiring sorbitol production at lower temperatures (below $5^{\circ}$ ) until this is halted by the hemolymph freezing solid. The role of G3PDH in both these processes is critical and is the subject of interest in this study. This investigation shows that $\mathrm{G} 3 \mathrm{PDH}$ from $5^{\circ}$ and $-15^{\circ} \mathrm{C}$ acclimated gall fly larvae has notably different kinetic properties, structural stability, and different phosphorylation and ubiquitination states.

In a previous study by our laboratory, gall fly G3PDH showed a difference in substrate affinity in the forward direction (DHAP $\rightarrow$ G3P) when assayed at lower temperatures (Storey and Storey, 1982). The addition of glycerol and sorbitol had no effect on the $\mathrm{K}_{\mathrm{m}}$ DHAP and NADH but did lower the activity of G3PDH. Also, no 
differences in these kinetic parameters were found between animals acclimated to $24^{\circ}$ versus $0^{\circ} \mathrm{C}$. While that study focused more on the forward G3P (\& glycerol) producing reaction under optimum glycerol synthesis temperatures, the current study looks at the reverse DHAP producing reaction in a comparison between the frozen and nonfrozen state. Indeed, a change in kinetic properties was observed in the $-15^{\circ} \mathrm{C}$ acclimated larvae with a $\sim 36 \%$ higher $\mathrm{K}_{\mathrm{m}} \mathrm{G} 3 \mathrm{P}$ than in the control larvae (Table 3.1). A reduction in catalytic efficiency in the reverse direction suggests a decrease in the capacity for triglyceride breakdown for shuttling of triose phosphates into glycolysis. Furthermore, it is a reduction in glycerol elimination as a result of the consumption of the substrate G3P. This is consistent with the gall fly's survival strategy of maintaining lipid and glycerol levels throughout the winter season. A similar strategy was observed in the wood frog, Rana sylvatica, that dephosphorylates its glycogen synthase kinase-3 in the frozen state to activate it, thereby allow it to deactivate glycogen synthase to halt glycogenesis. The wood frog builds-up glucose as a cryoprotectant and this mechanism allows it to maintain ultra-high glucose levels throughout its episodes of freezing without allowing them to be reconverted to glycogen (Dieni et al., 2012). The freeze-avoiding gall moth, Epiblema scudderiana, maintains an even higher concentration of glycerol than the gall fly $(\sim 2 \mathrm{M})$ and showed a two-fold increase in the $\mathrm{K}_{\mathrm{m}}$ glyceraldehyde of $-15^{\circ} \mathrm{C}$-acclimated larvae as compared to $5^{\circ} \mathrm{C}$ larvae for the alternative glycerol producing enzyme NADPH-linked polyol dehydrogenase (Holden and Storey, 2011) indicating that this strategy of regulating specific enzymes to help prevent reconversion of cryoprotectants into glycogen is a conserved and important response for cold-hardy animals over the winter months. 
When looking at the reverse direction of G3PDH (G3P $\rightarrow$ DHAP), an increase in G3P concentration might be expected to push the reaction. However, activity of glycerol kinase, the enzyme that converts glycerol to G3P, could not be stimulated in third instar gall fly larvae at any temperature (Storey and Storey, 1981). While accumulated glycerol is catabolized completely in gall fly larvae that are transitioning to pupae, it is thought that it may be through a novel route that uses polyol dehydrogenase and glyceraldehyde kinase (Morrissey and Baust, 1976; Joanisse and Storey, 1994). Indeed, glycerol levels were not observed to decrease in response to a temperature increase or any other stimulation in gall fly before the winter ended (Storey and Storey, 1981). Another alternative is that glycerol is catabolized in the spring only after induction of glycerol kinase.

With levels of glycerol reported as high as $430 \mu \mathrm{mol} / \mathrm{g}$ wet weight (Storey and Storey, 1983a) in the gall fly larvae, glycerol effects on the activity of G3PDH were of interest. Levels as high as $435 \mathrm{mM}$ of glycerol had no significant effect on G3PDH activity in vitro but at $900 \mathrm{mM}$ the activity of G3PDH from frozen larvae decreased by $\sim 30 \%$ while that of the control enzyme was statistically unchanged (Figure 3.2). It cannot be confirmed whether a direct interaction of glycerol and G3PDH is a regulatory mechanism that is reducing enzyme activity during the winter but it is clear that the G3PDH is designed to be suppressed in the frozen state. Sorbitol did not have any effect on the activity of G3PDH in either state (Figure 3.2).

The activity of G3PDH at optimal substrate concentrations may not reflect the true performance of the enzyme in vivo, which is why interactions between polyols and substrate affinity were investigated. The affinity for the cofactor $\mathrm{NAD}^{+}$did not change in 
the presence of high concentrations of glycerol $(893 \mathrm{mM})$ or sorbitol $(106 \mathrm{mM})$ but the $\mathrm{K}_{\mathrm{m}}$ G3P did show a differential response to polyols (Table 3.2). This level of glycerol decreased the $\mathrm{K}_{\mathrm{m}} \mathrm{G} 3 \mathrm{P}$ for G3PDH from frozen larvae but much less than it did for the control enzyme (Table 3.2). However, in the presence of sorbitol, G3PDH from control larvae showed a four-fold increase in G3P affinity (i.e. $\mathrm{K}_{\mathrm{m}}$ decreased) but sorbitol had no effect on the $\mathrm{K}_{\mathrm{m}} \mathrm{G} 3 \mathrm{P}$ of frozen G3PDH. Hence, regulation of G3PDH in gall fly larvae appears to rely heavily on modulating the affinity of the enzyme for G3P substrate to suppress G3PDH activity during freezing. This appears to be accomplished in part by creating an interaction between the enzyme and glycerol/sorbitol where the strong suppression of $\mathrm{K}_{\mathrm{m}} \mathrm{G} 3 \mathrm{P}$ of control G3PDH seen in the presence of either polyols is largely negated for the frozen enzyme (Table 3.2). In the presence of sorbitol, for example, this effectively resulted in a 6.5-fold increase in affinity (i.e. decrease in $\mathrm{K}_{\mathrm{m}}$ ) of the enzyme for G3P in the control state as compared to the comparable value for the frozen enzyme. The effect of glycerol may not be so prominent at more physiological concentrations and coupled with sorbitol, glycerol may not have a significant activation effect on G3PDH in frozen gall fly.

G3PDH structural stability seemed to be high based on an $\mathrm{I}_{50}$ urea of $3.5 \mathrm{M}$ for the control enzyme and a similar value for the enzyme from frozen larvae (Table 3.3). Interactions between $\mathrm{I}_{50}$ urea and the cryoprotectants glycerol and glucose revealed an effect by glycerol but not by glucose. Glycerol increased the $\mathrm{I}_{50}$ urea of frozen G3PDH by over $20 \%$ while it had no significant effect on the control enzyme, which could likely be as a result of competition by glycerol (Table 3.3). This may not offer enough supporting evidence of physiologically relevant stress-state stabilisation of the enzyme because of 
the minimal effect but it does reflect the differential kinetic and structural properties of the control and frozen forms of G3PDH.

The previous study by our laboratory on gall fly G3PDH found minor kinetic differences between warm and $0^{\circ} \mathrm{C}$-acclimated larvae but did not test for the presence of regulatory PTMs. The present study found that G3PDH from frozen gall fly larvae showed substantially less phosphorylation on all three phosphorylation sites tested as well as a significantly lower level of ubiquitination (Figure 3.3). Such a difference in phosphorylation states as a response to environmental stress is consistent with previous studies conducted on several enzymes and animal models (Storey and Storey, 2007; Plaxton and Storey 1984b; Whitwam and Storey 1990; Cowan and Storey, 1999; Greenway and Storey, 2000) including earlier studies of freeze-responsive changes in phosphorylation of ion motive ATPase enzymes in E. solidaginis (McMullen and Storey 2008a, 2010). Changes in phosphorylation state may be a principal regulatory mechanism that explains the change in kinetic properties and responses to glycerol, sorbitol and urea by G3PDH from control versus frozen larvae. However, ubiquitination is an additional PTM that could also be involved in this process. Ubiquitination was originally thought of as a one-way modification that set up proteins for degradation but more recently it's been found to also play a role in the reversible regulation of proteins in response to stress (Wang et al., 2001; Abboud and Storey, 2013; Katzenback et al., 2014). The increasing frequency of ubiquitin-related PTM regulatory discoveries is further confirming that this mechanism may be involved in the control of numerous pathways involving a complex interplay between many regulatory mechanisms. 
In conclusion, the activity of G3PDH is lowered and $\mathrm{K}_{\mathrm{m}} \mathrm{G} 3 \mathrm{P}$ is elevated in frozen gall fly larvae, as compared with controls, and the two enzyme forms are also differentially sensitive to glycerol and sorbitol. The molecular basis of this difference appears to be changes in enzyme PTMs, the enzyme from frozen larvae being a lowphosphate and low-ubiquitin form. Substrate affinity for G3P was lower for G3PDH from frozen larvae especially in the presence of sorbitol whereas control G3PDH had more of an activation response to sorbitol and glycerol. Maximal activity of frozen G3PDH was inhibited by high levels of glycerol and unaffected by sorbitol. Finally, while G3PDH showed a high structural stability, as assessed by urea effects, it was further increased slightly for frozen G3PDH in the presence of glycerol. While the structural changes do not have a functional significance in the gall fly's stress-responsive strategies, the reversible PTMs and the kinetic changes indicate an inhibition of G3PDH in the frozen state. This could likely be explained by a reduced need to channel G3P products from triglyceride breakdown or other sources into glycolysis in frozen larvae. 


\section{Chapter 4: \\ General Discussion}


Since insects must pass through many phases of development involving elaborate anatomical transformations, many physiological processes have to be impeccably timed with respect to changing seasons in order to have a successful life history. One of nature's tools that gives them leeway is diapause, which can suspend their development when food availability becomes low and allows them to resume where they left off upon the return of spring's buds and blossoms. In the cold Canadian winters, insects begin diapause only when they can commit for the whole winter. This means that they need to have the mechanisms needed to cope with the subzero temperatures and the generally low humidity of the winter months They also need mechanisms to assure sufficient metabolic fuels to last the whole winter and enough lipid and glycogen stores to support the transition to the next stage of development in the spring. For certain insects, this means switching off enzymatic pathways that breakdown and burn lipids, activating cryoprotectant producing pathways at the right temperature and, finally, reorganizing all their metabolic pathways to utilize exclusively the fuels that are dedicated for overwintering.

Two major strategies of cold hardiness are freeze tolerance and freeze avoidance, which both allow an organism to tolerate extremely low temperatures with one major difference. Freeze tolerance allows for ice formation in extracellular fluid spaces whereas freeze avoidance suppresses all freezing and emphasizes deep supercooling of body fluids. These mechanisms require high levels of low molecular weight cryoprotectants to be synthesized and the source is most often carbohydrates. Therefore, in both cases the intracellular SCP is depressed below the coldest temperatures typically experienced by the animal. In freeze tolerant species where extracellular freezing cuts off intercellular 
communication, metabolic pathways have to be adjusted to tolerate the changing levels of metabolites, the reduced ability to generate energy by means of oxidative catabolism, and the halting of fuel delivery to cells via the hemolymph. This requires quick and responsive changes to various key enzymatic reactions. In many other systems such controls are often effectively accomplished by reversible post-translational modifications (Storey and Storey, 2007; Plaxton and Storey 1984b; Whitwam and Storey 1990; Cowan and Storey, 1999; Greenway and Storey, 2000; McMullen and Storey 2008a, 2010). For this reason, the present study investigated the roles of PTMs in regulating an important glycolytic control point and the management of lipid and carbohydrate metabolism in association with polyol synthesis in a freeze-tolerance insect. The goldenrod gall fly larvae is a fitting model to examine the biochemical regulation that is associated with these survival mechanisms because of the large body of previous research available about many aspects of its winter metabolism and pathways of polyol synthesis.

Chapters 2 and 3 of this thesis examined enzymes that moderate carbohydrate metabolism and link lipid and polyol synthesis to glycolysis. Pyruvate kinase is the last enzyme in glycolysis where the fate of carbon is ultimately determined. In a glucose and oxygen rich environment, glycolysis would be highly active and directing its end product, pyruvate, towards the Krebs cycle for ATP production or towards various biosynthetic reactions (conversion to acetyl-CoA for fatty acid synthesis). In the absence of sufficient oxygen, the alternative for pyruvate is the anaerobic conversion to lactate. Glycerol-3phosphate dehydrogenase is an enzyme that links lipid and carbohydrate metabolism by diverting the glycolytic intermediate, DHAP, either out of or back into glycolysis. While both of these enzymes are subject to reversible PTMs in the gall fly, the effect of PTMs 
on their kinetic properties varies based on the specific role that they play in the cell. Glycerol is produced in gall fly larvae from both the PPP via NADPH-linked polyol dehydrogenase (Storey, 2004) and also further down glycolysis (via G3PDH). If glycerol was being produced by glycolysis alone under anoxic conditions, LDH would quickly be inactivated due to lack of NADH, which would mean that PK activity would be unnecessary and probably harmful. Furthermore, alanine levels would rise as a result of pyruvate transamination and there would be no net ATP production. Therefore, since four times more glycerol is produced than alanine in anoxia exposed gall fly larvae, the PPP must be a viable source of glycerol production and a highly active G3PDH would, in fact, pull much of the carbon out of glycolysis (Storey, 2004). However, since we know that lactate levels continue to rise during freeze exposure (Storey and Storey, 1985), there must be certain enzymes that are activated or inactivated to allow glycolysis to continue during glycerol production (prior to freezing) and after glycerol accumulation has ceased (post freezing). This change has to be reversible and quickly triggered to allow gall fly larvae to control the flow of carbon in response to temperature change, freeze/thaw, and energy needs. PTMs are expected to be the mechanism used to instill these reactions and are likely inhibiting G3PDH and activating PK in freeze exposed gall flies to allow for the balance of carbon flow through the PPP and glycolysis during anoxic conditions of freezing.

\section{Pyruvate Kinase}

There were apparently two forms of pyruvate kinase that could be found based on the state of the animal according to this study. The PK form in frozen larvae appeared to 
be active and catered to maintain functionality in the specific cellular environment found in winter gall fly larvae. Kinetic comparisons revealed that frozen PK had a lower substrate affinity for pyruvate under optimal assay conditions. However, in the presence of physiological levels of some metabolites found in high concentrations in the frozen state such as alanine and G3P substrate affinity was increased. Depending on the intracellular $\mathrm{pH}$ changes that take place in frozen gall fly larvae, substrate affinity may be differentially improved for frozen PK. Greater protein stability was observed in the frozen state; however, it was reduced in the presence of glucose and glycerol instead of increasing as seen for the control form of the enzyme. These changes were attributed to a greater relative protein phosphothreonine content found in frozen PK, which appears to be the main regulatory mechanism. Based on the knowledge that pyruvate is primarily used in frozen gall fly as a substrate for anaerobic fermentation, PK activity must be maintained to support long term energy demands over days, weeks or months in the frozen state. This activity accounts for the metabolic rate still observed in frozen gall fly and for the sustained slightly higher lactate concentrations that were noted in previous studies (Storey and Storey, 1985; 1986).

\section{Glycerol-3-phosphate Dehydrogenase}

During the cold-acclimation stage, gall fly larvae use G3PDH and glycerol-3phosphatase as a main glycerol synthesizing pathway. It is at this branch that G3PDH directs carbon away from glycolysis, producing G3P which under aerobic conditions can be used to provide the glyceride "backbone" for triglyceride synthesis or can be dephosphorylated to release free glycerol as a cryoprotectant at cold temperatures. 
However, in the reverse direction G3PDH can use products of triglyceride and phospholipids breakdown as well as the re-conversion of cryoprotectant glycerol to G3P (via the glycerol kinase reaction) and re-introduce G3P into glycolysis. When gall fly larvae pass the cryoprotectant production phase, they enter an inactive frozen state where all cryoprotectant synthesis ceases and there is no lipolysis for energy production. In the present study, G3PDH from frozen larvae was in fact dephosphorylated and deubiquitinated, which correlates with a lesser active form. Substrate affinity showed an overall decreasing trend for frozen G3PDH as well as lowered activity in the presence of high glycerol concentrations. G3PDH structural stability was slightly improved during freezing, and this may help to preserve the enzyme for spring when the larvae may activate lipogenic pathways during the pupation transition or for a renewed role in the G3PDH-G3P oxidase shuttle which is the mechanism used by insects to transfer reducing equivalents from the cytoplasm into the mitochondria (Sacktor, 1976). However, the reverse reaction of G3PDH was probably not as necessary for the gall fly because there is nearly no production of G3P from fatty acid break-down and glycerol phosphorylation during freezing.

\section{Conclusion}

This thesis demonstrated that the gall fly regulates two enzymes that were not previously reported as regulatory targets as part of the adaptation to freezing survival during the winter diapause of the third instar. Furthermore, these two enzymes are regulated by reversible PTMs, on one enzyme (PK) adding PTMs and on the other (G3PDH) removing these covalently bonded chemical groups. A role for PK was shown 
to be necessary and the enzyme operational during anaerobic glycolysis in frozen gall flies whereas the role of G3PDH, on the contrary, was less needed during this state. To illustrate, the PEP substrate affinity of frozen PK increased significantly in the presence of alanine and G3P, which appears to help maintain activity in a state where the animal relies exclusively on glycolysis for energy production.

\section{Future Directions}

Now that the importance of these enzymes has been established in the survival of the gall fly, the door is open to build on these metabolic focal points in future studies. We have seen that PK shows consistent activity during freezing but not many experiments were done at lower temperatures. The first step would be to measure the activation energy and $\mathrm{Q}_{10}$ (increase in velocity per $10^{\circ} \mathrm{C}$ increase) using an Arrhenius plot and repeat the same for both enzyme forms. This could establish a baseline of the activity change due directly to the structural alteration from PTMs. Subsequently, all the kinetic parameters measured could be repeated in an assay temperature closer to $0^{\circ} \mathrm{C}$ to see if the temperature change is a factor in the regulation of PK. For example, it was found that a mere $13^{\circ} \mathrm{C}$ decrease of the assay temperature resulted in a reduction of substrate $\mathrm{K}_{\mathrm{m}}$ by nearly one-half for LDH in the wood frog (Abboud and Storey, 2013).

Broadening the perspective on PK, a subsequent branch should be explored because several oxidative pathways are shut down in frozen gall fly larvae. However, the anaerobic branch that pyruvate can follow - conversion to lactate - remains available and is catalyzed by LDH. A study dedicated entirely to examining the differences in LDH from warm-acclimated and subzero-acclimated gall fly could complete the picture of the 
role that PK plays in the hypometabolic state. Additionally, there is a strong possibility that LDH is also regulated by reversible PTMs because this has been demonstrated recently in several animal systems (Xiong and Storey, 2012; Abboud and Storey, 2013; Katzenback et al., 2014; Shahriari et al., 2013; Dawson et al., 2013). Since glycolysis is a short pathway that ends in lactic acid and generates much less ATP than the oxidative phosphorylation pathway, it is curious as to how gall flies experience a very slow and moderate rise in levels of lactic acid (from 1 to $3.39 \mu \mathrm{mol} / \mathrm{g}$ wet wt.) only after prolonged exposure to freezing (Storey and Storey, 1985). Studies on LDH in the gall fly could tell whether it is inhibited after a certain level of energy reserves have been depleted or if a different source of ATP production is relied upon in the frozen larvae such as the succinate thiokinase reaction (Kiss et al., 2014).

The importance of polyol cryoprotectants in winter hardiness of gall fly larvae is undisputed; however, this thesis learned more about glycerol management than it did about sorbitol. Since sorbitol is just as critical as glycerol and maybe even more in the presence of subzero temperatures, it would be valuable to further explore the principles of the sorbitol-producing pathway. Sorbitol production was demonstrated to take the route of glucose-6-phosphate $\rightarrow$ glucose $\rightarrow$ sorbitol using the enzymes glucose-6-phosphatase and NADPH-linked polyol dehydrogenase (Joanisse and Storey, 1994). Additionally, unlike glycerol, sorbitol levels can be readily reversible depending on winter temperatures and are triggered at much colder temperatures $\left(\sim 0^{\circ} \mathrm{C}\right)$ than for glycerol (Storey and Storey, 1986). Therefore, while both of these enzymes should be studied, NADPH-linked polyol dehydrogenase may be a slightly better candidate as a next step because it has already been shown to be reversibly phosphorylated and regulated in the 
goldenrod gall moth (Epiblema scudderiana), a species that uses the freeze avoidance supercooling strategy of subzero survival (Holden and Storey, 2011). As mentioned before, the gall moth makes an excellent animal model to study in concert with the gall fly because galls of both species can frequently be found on the same stem of a goldenrod plant and yet they use two very different approaches to winter cold hardiness. Since there has been a study conducted on PDH and since this enzyme is involved in glycerol production in the gall moth, it would be interesting to compare its function and regulation in the gall fly. 


\section{References}

Abboud J, Storey KB. 2013. Novel control of lactate dehydrogenase from the freeze tolerant wood frog: role of posttranslational modifications. PeerJ. 1:e12.

Alarcon DA, Nandi M, Carpena X, Fitaa I, Loewen PC. 2012. Structure of glycerol-3phosphate dehydrogenase (GPD1) from Saccharomyces cerevisiae at $2.45 \AA$ resolution. Acta Cryst. F68:1279-1283.

Ballantyne JS, Storey KB. 1985. Characterization of mitochondria isolated from the freezing-tolerant larvae of the goldenrod gall fly (Eurosta solidaginis): substrate preferences, salt effects, and $\mathrm{pH}$ effects on warm- and cold-acclimated animals. Can J Zool. 63:373-79.

Baust JG, Lee RE Jr. 1983. Population differences in antifreeze cryoprotectant accumulation patterns in an Antarctic insect. Oikos. 40:120-124.

Ciechanover A, Finley D, Varshavsky A. 1984. Ubiquitin dependence of selective protein degradation demonstrated in the mammalian cell cycle mutant ts85. Cell. 37:5766.

Cohen P. 2002. The origins of protein phosphorylation. Nat Cell Biol. 4E:127-30.

Collier GE, Murphy WJ. 1997. A molecular phylogeny for aplocheiloid fishes (Atherinomorpha, Cyprinodontiformes): the role of vicariance and the origins of annualism. Mol Biol Evol. 14(8):790-9.

Cowan KJ, Storey KB. 1999. Reversible phosphorylation control of skeletal muscle pyruvate kinase and phosphofructokinase during estivation in the spadefoot toad, Scaphiopus couchii. Mol Cell Biochem. 195:173-181.

Danks HV. 1978. Modes of seasonal adaptations in the insects. I. Winter survival. Can Ent. 110:1167-1205.

Dawson NJ, Bell RA, Storey KB. 2013. Purification and properties of white muscle lactate dehydrogenase from the anoxia-tolerant turtle, the red-eared slider, Trachemys scripta elegans. Enzyme Res. 2013:784973.

de la Roche M, Tessier SN, Storey KB. 2012. Structural and functional properties of clycerol-3-phosphate dehydrogenase from a mammalian hibernator. Protein J. 31:109-119.

Dickson RC. 1949. Factors governing the induction of diapause in the oriiental fruit moth. Ann Entomol Soc Am. 42:511-37.

Dieni CA, Bouffard MC, Storey KB. 2012. Glycogen synthase kinase-3: cryoprotection and glycogen metabolism in the freeze-tolerant wood frog. $J$ Exp Biol. 215(3):543-51. 
Gantz JD, Lee RE Jr. 2014. The limits of drought-induced rapid cold-hardening: Extremely brief, mild desiccation triggers enhanced freeze-tolerance in Eurosta solidaginis larvae. J Insect Physiol. 73C:30-6.

Greenway SC, Storey KB. 2000. Seasonal change and prolonged anoxia affect the kinetic properties of phosphofructokinase and pyruvate kinase in oysters. J Comp Physiol B. 170:285-93.

Hayward SAL, Rinehart JP, Sandro LH, Lee RE Jr, Denlinger DL. 2007. Slow dehydration promotes desiccation and freeze tolerance in the Antarctic midge Belgica antarctica. J Exp Biol. 210: 836-44.

Heisler N, Weitz H, Weitz MA. 1976. Extracellular and intracellular pH with changes of temperature in the dogfish Scyliorhinus stellaris. Resp Physiol. 26: 249-63.

Hershko A. 1983. Ubiquitin: roles in protein modification and breakdown. Cell. 34:11-2.

Holden CP, Storey KB. 1994. 6-Phosphogluconate dehydrogenase from a tolerant insect: control of the hexose monophosphate shunt and NADPH production during cryoprotectant synthesis. Insect Biochem Molec Biol. 24(2):167-73.

Holden HA, Storey KB. 2011. Reversible phosphorylation regulation of NADPH-linked polyol dehydrogenase in the freeze-avoiding gall moth, Epiblema scudderiana: role in glycerol metabolism. Arch Insect Biochem Physiol. 77(1):32-44.

Ip YT, Davis RJ. 1998. Signal transduction by the c-Jun N-terminal kinase (JNK)-from inflammation to development. Curr Opin Cell Biol. 10(2):205-19.

Irwin JT, Lee RE Jr. 2002. Energy and water conservation in frozen vs. supercooled larvae of the goldenrod gall fly, Eurosta solidaginis (Fitch) (Diptera: Tephritidae). J Exp Zool. 292(4):345-50.

Izadi H, Heydari M. 2014. Effects of seasonal acclimation on cold tolerance and biochemical status of the carob moth, Ectomyelois ceratoniae Zeller, last instar larvae. Bull Entomol Res. 104:592-600.

Joanisse DR, Storey KB. 1994. Enzyme activity profiles in an overwintering population of freeze-tolerant larvae of the gall fly, Eurosta solidaginis. J Comp Physiol B. $164: 247-255$.

Joanisse DR, Storey KB. 1996. Fatty acid content and enzymes of fatty acid metabolism in overwintering cold-hardy gall insects. Physiol Zool. 69(5):1079-95.

Katzenback BA, Dawson NJ, Storey KB. 2014. Purification and characterization of a urea sensitive lactate dehydrogenase from the liver of the African clawed frog, Xenopus laevis. J Comp Physiol B. 184(5):601-11. 
Kim J, Lee J, Kim HK, Han Y-M. 2008. Pyruvate kinase isozyme type M2 (PKM2) interacts and cooperates with Oct-4 in regulating transcription. Int J Biochem Cell Biol. 40:1043-54.

Kiss G, Konrad C, Pour-Ghaz I, Mansour JJ, Németh B, Starkov AA, Adam-Vizi V, Chinopoulos C. 2014. Mitochondrial diaphorases as $\mathrm{NAD}^{+}$donors to segments of the citric acid cycle that support substrate-level phosphorylation yielding ATP during respiratory inhibition. FASEB J. 28(4):1682-97.

Lane N. 2009. Life Ascending: The Ten Great Inventions of Evolution. New York: W.W. Norton \& Co.

Larsson C, Påhlman IL, Ansell R, Rigoulet M, Adler L, Gustafsson L. 1998. The importance of the glycerol 3-phosphate shuttle during aerobic growth of Saccharomyces cerevisiae. Yeast. 14:347-57.

Lee RE Jr, Baust JG. 1981. Seasonal patterns of cold-hardiness in Antarctic terrestrial arthropods. Comp Biochem Physiol. 70A:579-82.

Lee RE Jr, Dommell RA, Joplin KH, Denlinger DL. 1995. Cryobiology of the freezetolerant gall fly Eurosta solidaginis: overwintering energetics and heat shock proteins. Clim Res. 5:61-7.

Lee RE Jr, Lewis EA. 1985. Effect of temperature and durationb of exposure on tissue ice formation in the gall fly, Eurosta solidaginis (Diptera, Tephritidae). Cryo-Lett. 6:25-34.

Levin DB, Danks HV, Barber SA. 2003. Variations in mitochondrial DNA and gene transcription in freezing-tolerant larvae of Eurosta solidaginis (Diptera: Tephritidae) and Gynaephora groenlandica (Lepidoptera: Lymantriidae). Insect Mol Biol. 12(3):281-9.

Malan A, Wilson LT, Reeves RB, 1976. Intracellular pH in cold-blooded vertebrates as a function of body temperature. Resp Physiol. 28:29-47.

McMullen DC, Storey KB. 2008. Mitochondria of cold hardy insects: responses to cold and hypoxia assessed at enzymatic, mRNA and DNA levels. Insect Biochem Mol Biol. 38:367-73.

McMullen DC, Storey KB. 2010. In cold-hardy insects, seasonal, temperature, and reversible phosphorylation controls regulate sarco/endoplasmic reticulum $\mathrm{Ca}^{2+}$ ATPase (SERCA). Physiol Biochem Zool. 8:677-86.

Michaelidis B, Storey KB. 1990. Interactions of temperature and $\mathrm{pH}$ on the regulatory properties of pyruvate kinase from organs of a marine mollusc. $J$ Exp Mar Biol Ecol. 140:187-196. 
Morrissey RE, Baust JG. 1976. The ontogeny of cold tolerance in the gall fly, Eurosta solidaginsis. J Insect Physiol. 22:431-437.

Pearson G, Robinson F, Beers Gibson T, Xu BE, Karandikar M, Berman K, Cobb MH. 2001. Mitogen-activated protein (MAP) kinase pathways: regulation and physiological functions. Endocr Rev. 22(2):153-83.

Plaxton WC, Storey KB. 1984a. Purification and properties of aerobic and anoxic forms of pyruvate kinase from red muscle tissue of the channelled whelk, Busycotypus canaliculatum. Eur J Biochem. 143:257-65.

Plaxton WC, Storey KB. 1984b. Phosphorylation in vivo of red-muscle pyruvate kinase from the channelled whelk, Busycotypus canaliculatum, in response to anoxic stress. Eur J Biochem. 143:267-72.

Reeves RB. 1972. An imidazole alphastat hypothesis for vertebrate acid-base regulation: tissue carbon dioxide content and body temperature in bullfrogs. Resp Physiol. $14: 219-236$.

Reeves RB, Malan A. 1976. Model studies of intracellular acid-base temperature responses in ectotherms. Resp Physiol. 28:49-63.

Rider MH, Hussain N, Dilworth SM, Storey JM, Storey KB. 2011. AMP-activated protein kinase and metabolic regulation in cold-hardy insects. $J$ Insect Physiol. 57(11):1453-62.

Shen W, Wei Y, Dauk M, Zheng Z, Zou J. 2003. Identification of a mitochondrial glycerol-3-phosphate dehydrogenase from Arabidopsis thaliana: evidence for a mitochondrial glycerol-3-phosphate shuttle in plants. FEBS Lett. 536(1-3):92-6.

Sacktor B. 1976. Biochemical adaptations for flight in the insect. Biochem Soc Symp. 41:111-31.

Shahriari A, Dawson NJ, Bell RA, Storey KB. 2013. Stable suppression of lactate dehydrogenase activity during anoxia in the foot muscle of Littorina littorea and the potential role of acetylation as a novel posttranslational regulatory mechanism. Enzyme Res. 2013:461374.

Storey KB. 2004. Cold hardiness and freeze tolerance In: Functional Metabolism: Regulation and Adaptation. Wiley-Liss, Hoboken, NJ, pp. 473-503.

Storey JM, Storey KB . 1982. Kinetic properties and regulation of glycerol-3-phosphate dehydrogenase from the overwintering, freezing-tolerant call fly larva, Eurosta solidaginis. Cryobiology. 19:185-94.

Storey JM, Storey KB. 1985. Freezing and cellular metabolism in the gall fly larva, Eurosta solidaginis. J Comp Physiol B. 155:333-7. 
Storey JM, Storey KB. 1983a. Regulation of cryoprotectant metabolism in the overwintering gall fly larva, Eurosta solidaginis: temperature control of glycerol and sorbitol levels. J Comp Physiol. 149:495-502.

Storey JM, Storey KB. 1986. Winter survival of the gall fly larva, Eurosta solidaginis: profiles of fuel reserves and cryoprotectants in a natural population. $J$ Insect Physiol. 32(6):549-55.

Storey KB, Storey JM. 1981. Biochemical strategies of overwintering in the gall fly larva, Eurosta solidaginis: effect of low temperature acclimation on the activities of enzymes of intermediary metabolism. J Comp Physiol. 144:191-9.

Storey KB, Storey JM. 1983b. Biochemistry of freeze tolerance in terrestrial insects. Trends Biochem Sci. 8(7):242-5.

Storey KB, Storey JM. 1991. Biochemistry of cryoprotectants. In Insects at Low Temperature, edited by Denlinger D, Lee RE, Chapman \& Hall, New York, pp. 64-93.

Storey KB, Storey JM. 1992. Biochemical adaptations for winter survival in insects. In: Advances in Low Temperature Biology, Vol. 1, edited by Steponkus PL, JAI Press, London, pp. 101-40.

Storey KB, Storey JM. 2007. Putting life on "pause" - molecular regulation of hypometabolism. J Exp Biol. 210:1700-14.

Storey KB, Storey JM. 2012. Insect cold hardiness: metabolic, gene, and protein adaptation. Can J Zool. 90:456-75.

Storey KB, Baust JG, Buescher P. 1981a. Determination of water "bound" by soluble subcellular components during low-temperature acclimation in the gall fly larva, Eurosta solidagensis. Cryobiology. 18(3):315-21.

Storey KB, Baust JG, Storey JM. 1981b. Intermediary metabolism during low temperature acclimation in the overwintering gall fly larva, Eurosta solidaginis. $J$ Comp Physiol. 144:183-90.

Storey KB, Keefe D, Kourtz L, Storey JM. 1991. Glucose-6-phosphate dehydrogenase in cold hardy insects: kinetic properties, freezing stabilization, and control of hexose monophosphate shunt activity. Insect Biochem. 21(2):157-61.

Storey KB, Micelli M, Butler KW, Smith ICP, Deslauriers R. 1984. 31P NMR studies of metabolism in the freeze tolerant larvae of the gall fly, Eurosta solidaginis. Eur J Biochem. 142:591-595.

Tauber MJ, Tauber CA, Masaki S. 1986. Seasonal Adaptations of Insects. Oxford University Press, 414 pp. 
Triplehorn CA, Johnson NF. 2005. Introduction to the Study of Insects, 7th Edition, Borror and Delong.

Wagner DL. 2009. Caterpillars of Eastern North America. Encyclopedia of Insects, 2nd Edition, edited by Resh VH and Cardé RT.

Wang C, Deng L, Hong M, Akkaraju GR, Inoue J, Chen ZJ. 2001. TAK1 is a ubiquitindependent kinase of MKK and IKK. Nature. 412:346-51.

Whitwam RE, Storey KB. 1990. Pyruvate kinase from the land snail Otala lactea: Regulation by reversible phosphorylation during estivation and anoxia. $J \operatorname{Exp}$ Biol. 154:321-37.

Xiong ZJ, Storey KB. 2012. Regulation of liver lactate dehydrogenase by reversible phosphorylation in response to anoxia in a freshwater turtle. Comp Biochem Physiol B. 163:221-8.

Zachariassen KE. 1980. The role of polyols and nucleating agents in cold-hardy beetles. $J$ Comp Physiol. 140:227-34. 